\title{
Focus on 1,25-Dihydroxyvitamin D3 in the Peripheral Nervous System
}

\author{
Pierre Antoine Faye ${ }^{1,2 t}$, François Poumeaud ${ }^{11}$, Federica Miressi ${ }^{1}$, Anne Sophie Lia ${ }^{1,2}$, \\ Claire Demiot ${ }^{1}$, Laurent Magy ${ }^{3}$, Frédéric Favreau ${ }^{1,2 *}$ and Franck G. Sturtz ${ }^{1,2 *}$ \\ 'EA 6309, Myelin Maintenance and Peripheral Neuropathies, Faculties of Medicine and Pharmacy, University of Limoges, \\ Limoges, France, ${ }^{2}$ Department of Biochemistry and Molecular Genetics, University Hospital of Limoges, Limoges, France, \\ ${ }^{3} \mathrm{CHU}$ de Limoges, Reference Center for Rare Peripheral Neuropathies, Department of Neurology, Limoges, France
}

In this review, we draw attention to the roles of calcitriol (1,25-dihydroxyvitamin D3) in the trophicity of the peripheral nervous system. Calcitriol has long been known to be crucial in phosphocalcium homeostasis. However, recent discoveries concerning its involvement in the immune system, anti-cancer defenses, and central nervous system development suggest a more pleiotropic role than previously thought. Several studies have highlighted the impact of calcitriol deficiency as a promoting factor of various central neurological diseases, such as multiple sclerosis, amyotrophic lateral sclerosis, Parkinson's disease, and Alzheimer's disease. Based on these findings and recent publications, a greater role for calcitriol may be envisioned in the peripheral nervous system. Indeed, calcitriol is involved in myelination, axonal homogeneity of peripheral nerves, and neuronal-cell differentiation. This may have useful clinical consequences, as calcitriol supplementation may be a simple means to avoid the onset and/or development of peripheral nervous-system disorders.

Keywords: calcitriol, peripheral nervous system, neuronal-cell differentiation, synergistic effects, myelin process

\section{EPIDEMIOLOGICAL DATA AND THE GENERAL FUNCTION OF VITAMIN D3}

For decades, the role of calcitriol was thought to be limited to phosphocalcium metabolism. Recent results have highlighted the role of this hormone in other functions (Garabédian, 2000; Christakos et al., 2016), which include the regulation of tissue proliferation, cell differentiation, and apoptosis, as well as regulation of the cardiovascular and immune systems. Indeed, the active form of vitamin D3 has been shown to regulate inflammation by regulating the synthesis of several cytokines and lymphocyte migration, with anti-cancer activities (Baeke et al., 2010). Based on cellular and animal models, Kalueff and Tuohimaa (2007) suggest that calcitriol has a major role in the genesis, development, and maintenance of central nervous system in adulthood. As shown in animal experiments, calcitriol may regulate rat brain development. Rats born to a mother that was vitamin D3-depleted during pregnancy were shown to have brain malformations, such as cortical atrophy associated with ventricular dilation (Eyles et al., 2005). Another study has reported the synthesis of calcitriol within the central nervous system, thus regulating its functioning and exerting neuroprotective effects (Eyles et al., 2003). Marini et al. (2010) observed that in vitro calcitriol delays cell proliferation and induces cell differentiation in HN9.10 embryonic hippocampal cells, with the formation of axons and dendrites. Overall, these findings suggest that vitamin D3 has activities 
similar to other neuroactive steroids in the central nervous system (Emmanuel et al., 2002; Melcangi and Panzica, 2009). However, the exact role of calcitriol in the peripheral nervous system is still unclear. The aim of this review was to gather available data concerning the role of calcitriol in the peripheral nervous system during its development and maintenance.

Although all the calcitriol functions may not yet be known, the chemical characteristics have been extensively investigated. The precursor of calcitriol is vitamin D or calciferol, which is synthesized in the skin or ingested with food. This precursor is biologically inactive and subjected to double hydroxylation, first in the liver and then in the kidney, to produce the biologically active compound, 1,25- $(\mathrm{OH})_{2}$-vitamin D3 or calcitriol (Figure 1). It is well known to regulate the expression of numerous target genes through the nuclear vitamin D receptor (VDR), which belongs to a common family of steroid receptors that also includes steroid, glucocorticoid, and retinoic acid receptors (Kalueff and Tuohimaa, 2007). Vitamin D deficiency is widely found worldwide (Holick, 2006). For example, the prevalence of vitamin D insufficiency was $77 \%$ in the United States population in 2004 (Ginde et al., 2009). However, reference values vary widely between countries. According to Rosen (2011) only 25-OH-vitamin D3 prohormone blood levels can accurately estimate vitamin D3 input from cutaneous synthesis and dietary intake, in contrast to 1,25$(\mathrm{OH})_{2}$-vitamin D3. The measurement of 1,25- $(\mathrm{OH})_{2}$-vitamin D3 is mainly reserved for patients with kidney insufficiency. Several countries consider that serum levels of 25-OH-vitamin D3 below $10 \mathrm{ng} / \mathrm{ml}$ indicate vitamin D deficiency. Vitamin D "insufficiency" is characterized by serum levels between 10 and $30 \mathrm{ng} / \mathrm{ml}$, an "appropriate" level between 30 and $100 \mathrm{ng} / \mathrm{ml}$, and a "toxic" level by values above $100 \mathrm{ng} / \mathrm{ml}$ (Rosen, 2011). However, in the United States, the Endocrine Society has established different threshold levels. Vitamin D deficiency is diagnosed in patients with serum levels of 25-OH-vitamin D3 below $20 \mathrm{ng} / \mathrm{ml}$, "sufficiency" between 30 and $40 \mathrm{ng} / \mathrm{ml}$, and toxicity above $50 \mathrm{ng} / \mathrm{ml}$ (Ross et al., 2011). In addition, these different thresholds are those used to measure phosphocalcium homeostasis. These thresholds could be different for other functions of the nervous system and, if so, they are yet to be determined.

\section{MECHANISTIC AND MOLECULAR INTERACTIONS OF VITAMIN D3}

Systemic action of Vitamin D3 requires a metabolization and an activation. Vitamin D3 metabolism is a multiple-step multipleorgan process which will be recalled thereafter. Once activated vitamin D3 will act upon several genes at a transcriptional level, in cooperation with other factors such as fat-soluble vitamin derivatives.

\section{Vitamin D3 Metabolism}

Calcitriol levels are precisely regulated by the mitochondrial hydroxylases, cytochrome P450C1 $\alpha$ (CYP27B1) and P450C24 (CYP24), which catalyze the bioactivation and degradation of vitamin D3 metabolites in most target cells
(Hii and Ferrante, 2016). The blood level of calcitriol is autoregulated through the stimulation of the CYP24 enzyme (VanAmerongen et al., 2004). In addition, calcitriol also inhibits CYP1 (renal $1 \propto$ hydroxylase involved in the second hydroxylation of vitamin D3) activity, thus forming a negative feedback loop to maintain normal levels (Issa et al., 1998). Finally, most calcitriol is excreted as calcitroic acid. The serum half-life of $1,25-(\mathrm{OH})_{2}$-vitamin D3 is approximately $4-6 \mathrm{~h}$, whereas the serum half-life of 25-OH-vitamin D3 is approximately 10-21 days (Kumar, 1986). These different serum half-lives explain why 25-OH-vitamin D3 is the classical form used in serum-level measurements in humans to evaluate the body level of vitamin D3. In addition, standard protocols in the clinical lab appear to be poorly adapted to measure calcitriol levels. Indeed, liquid chromatography coupled to tandem mass spectrometry (LC-MS/MS) appears to be the most appropriate, but it is expensive and not used by most laboratories (Spanaus and von Eckardstein, 2017). This sensitive technique is used for calcitriol measurement because absolute levels of 25-OH-vitamin D3 and $1,25-(\mathrm{OH})_{2}$-vitamin D3 differ by a factor of 1000 . The renal 1-alpha hydroxylation of $25-\mathrm{OH}$-vitamin $\mathrm{D} 3$ to $1,25-(\mathrm{OH})_{2}$ vitamin D3 is highly regulated by the serum concentration of parathyroid hormone, calcium, and phosphate. It is well known that a wide variety of extra-renal cells can produce calcitriol from 25-OH-vitamin D3 by the enzyme $1 \alpha$ hydroxylase in vitro, including activated macrophages, keratinocytes, and cells of the central nervous system, such as neurons and microglial cells. However, the regulation of hydroxylation in these cells has not been fully explored and such production of calcitriol appears to not be finely regulated by renal production (VanAmerongen et al., 2004). Most circulating vitamin D metabolites in blood under normal physiological conditions are bound to vitamin D-binding protein or albumin and transported to a large number of target organs (VanAmerongen et al., 2004).

\section{Vitamin D3 and the Vitamin D Receptor (VDR)}

Vitamin D is converted into its hydroxylated derivative, 1,25$(\mathrm{OH})_{2}$-vitamin D3, by two successive hydroxylations, one in the liver and one in the kidneys. Its liposolubility allows calcitriol to pass through cell membranes without a transporter. Within the cell, the vitamin D receptor (VDR), a member of the nuclear-receptor superfamily, mediates the biological activity of $1,25-(\mathrm{OH})_{2}$-vitamin D3 by regulating gene expression, similarly to other steroid hormone receptors (Figure 2). Following a conformational change, the VDR regulates gene transcription by binding to hexameric core-binding motifs in the promoter regions of target genes (Issa et al., 1998). The vitamin D-VDR endocrine system has been identified in nearly all nucleated cells. Microscopic autoradiography of the VDR has identified the target organs for vitamin D, especially the brain and spinal cord, for which there is a high binding rate (Stumpf, 2012). Although not fully understood, VDR could be involved in the development of a variety of neurological illnesses.

When entering a target cell, calcitriol dissociates from vitamin D-binding protein (the transporter of vitamin D in blood), 


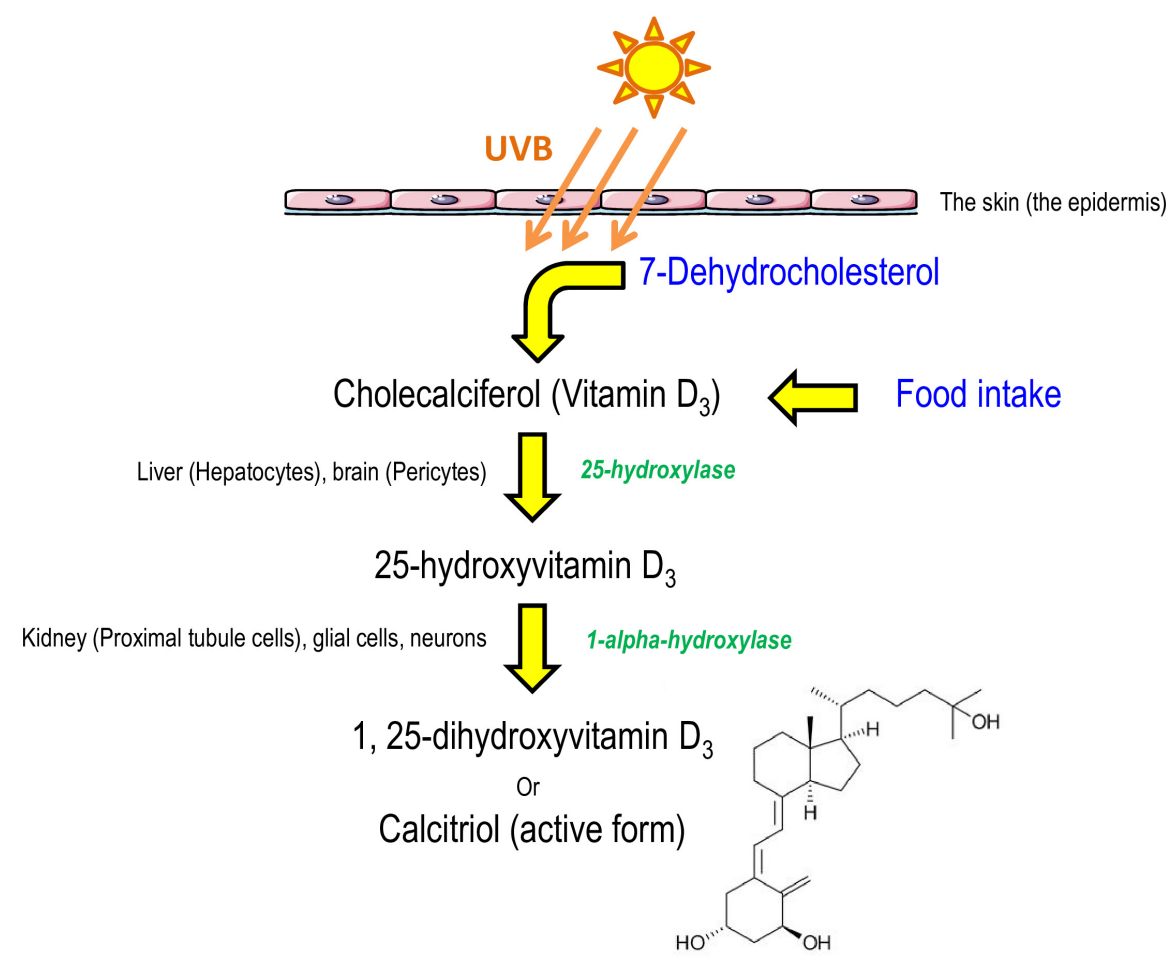

FIGURE 1 | Schematic representation of calcitriol synthesis in humans. Cholecalciferol, from food intake or derived from 7-dehydrocholesterol after sun exposition, is converted to calcitriol, the active form, by two hydroxylations (Emmanuel et al., 2002; Eyles et al., 2005; El-Atifi et al., 2015).

\section{1, 25-dihydroxyvitamin $D_{3}$}

Or

Calcitriol (active form)

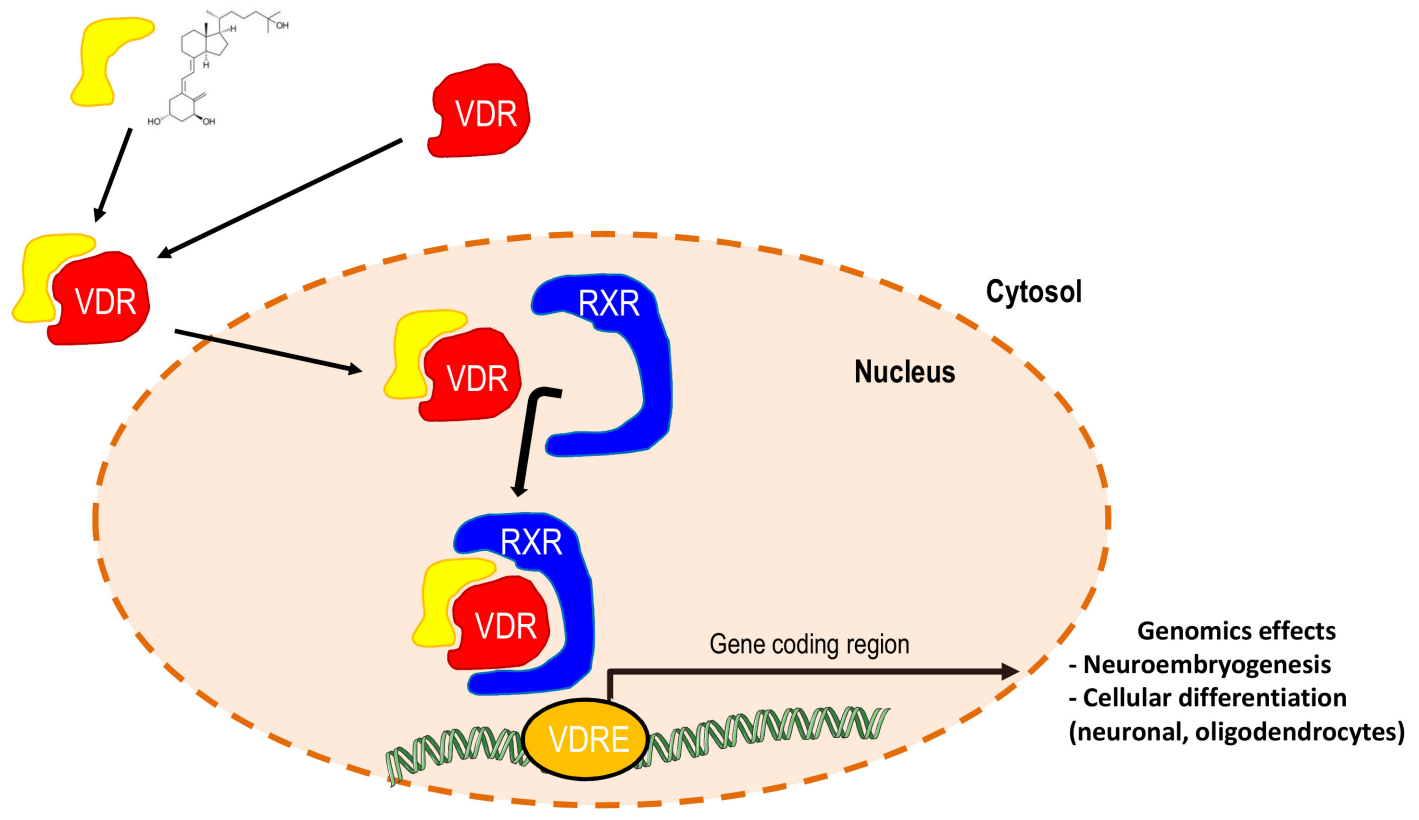

FIGURE 2 | Schematic representation of the synergetic effects of calcitriol and the retinoid X receptor on the expression of genes with neuronal roles. RXR, retinoid X receptor; VDR, vitamin $\mathrm{D}_{3}$ receptor; VDRE, VDR responsive element. 
diffuses across the plasma membrane, binds to the VDR, and the formed complex migrates to the nucleus. The activated VDR dimerizes with another nuclear receptor, the retinoic acid receptor (RXR). This RXR/VDR/calcitriol heterodimer binds to the vitamin $\mathrm{D}$ responsive element (VDRE), a specific sequence in the promoter region of target genes. Upon binding to the VDRE, the heterodimer activates or suppresses gene transcription. VDRs can also form homodimers but their functional significance is not known (VanAmerongen et al., 2004). In addition, efficient transcription requires co-activator or co-repressor proteins, such as Smad3, an effector of the TGF beta pathway (VanAmerongen et al., 2004). In the calcitriol pathway, Smad 3 acts as a coactivator and Smad 7 abrogates the Smad3-mediated VDR response. Cells of the central nervous system (microglia, neurons, and astrocytes) express VDR and can respond directly to calcitriol (Emmanuel et al., 2002).

Calcitriol has also been reported to modulate rapid nongenomic actions mediated through various mechanisms, such as the activation of G-protein coupled receptors and downstream protein kinase $\mathrm{C}$ (PKC), mitogen-activated protein kinase (MAPK) pathways, phospholipases A2 and C, and the opening of $\mathrm{Ca}^{2+}$ and $\mathrm{Cl}^{-}$channels (Buitrago et al., 2013; Hii and Ferrante, 2016). However, these various effects have yet to be reported in cells of the nervous system.

\section{Vitamin D3 and Synergistic Effects With Other Vitamins}

The synergistic interactions between fat-soluble vitamins have been suggested since several decades and particularly between vitamin $\mathrm{A}$ and vitamin $\mathrm{E}$ in the field of lipid peroxidation (Tesoriere et al., 1996). However, the interaction of vitamin D3 with other fat-soluble vitamins is also suggested through different mechanisms and based on different responses induced by vitamin D3 in vitro or in vivo. Indeed, vitamin D3 has been shown to regulate the growth and differentiation of a number of various cell types in vitro, including bone, immune and hematopoietic cells, and keratinocytes, as well as cancer cells. However, in vivo, these responses are achieved at toxic doses that cause severe hypercalcemia (Issa et al., 1998). These observations suggest that the effects of calcitriol underline synergistic effects between other hormones or molecules at lower concentrations.

Firstly, vitamin D3 appears to have synergistic effects with other fat-soluble vitamins, such as vitamin $\mathrm{K}$, particularly for bone and cardiovascular health (van Ballegooijen et al., 2017b). Regarding bone homeostasis, in an experimental study, Kerner et al. (1989) described that osteoblast-specific expression of osteocalcin, a vitamin $\mathrm{K}$-dependent protein, is controlled at the transcriptional level by the calcitriol within the promoter of the osteocalcin gene. These results were supported by Sergeev et al. (1987), in a rat model, showing that VDR can undergo gamma-carboxylation in the presence of vitamin $\mathrm{K}$, which putatively interferes with its nuclear functions through VDREs. In an experimental study investigating osteoporosis in ovariectomized rats, Matsunaga et al. (1999) reported that the combined treatment with vitamin D3 and $\mathrm{K}$ is more effective to prevent osteoporosis. In observational studies in humans, these interactions were also pointed out. In 387 hemodialyzed patients, vitamin D3 analog users present higher concentrations of bone Gla protein (BGD) indicating the role of vitamin D3 to stimulate this vitamin K-depend proteins (Fusaro et al., 2016). In the NOREPOS study among 1318 older adults, results underlined that a combination of vitamin D3 and $\mathrm{K}$ supplementations at low concentrations was linked with a greater hip fracture risk compared to supplementations at high concentrations or to the group supplemented with just one vitamin at low concentrations (Finnes et al., 2016). Several clinical trials support this synergetic interaction and particularly in postmenopausal osteoporosis (van Ballegooijen et al., 2017b). For instance, in an interventional, randomized and placebo-controlled study led in 172 Japanese post-menopausal women with osteopenia and osteoporosis, results showed that only vitamin K plus vitamin D3 increased bone mineral density (Ushiroyama et al., 2002). In 78 Korean post-menopausal women over 60 years of age, vitamin $\mathrm{K}$ treatment associated to vitamin $\mathrm{D}$ and calcium increased bone mineral density (Je et al., 2011). Regarding cardiovascular health, the synergy between vitamin D3 and $\mathrm{K}$ was also reported. Similarly, this synergy could be linked to vitamin D3-induced stimulation of vitamin K-dependent proteins, such as matrix Gla protein (MGP), which needs gamma-glutamate carboxylation to inhibit the vascular calcification (Mayer et al., 2017). Indeed, in a rodent model, vitamin $\mathrm{K}$ deficiency caused by warfarin treatment, promotes arterial calcifications and this occurs earlier when high doses of vitamin D are associated (Price et al., 2000). A prospective study indicates that the combined treatment of low dose of vitamin $\mathrm{D}$ and a low status of vitamin $\mathrm{K}$ promoted systolic and diastolic blood pressures increase and hypertension after 6 years of follow up (van Ballegooijen et al., 2017a). These results were supported by another study showing that this association induces a significantly higher aortic pulse wave than in subjects with isolated vitamin D3 or vitamin $\mathrm{K}$ deficiency, reflecting a higher aortic resistance (Mayer et al., 2017). In addition, a randomized and double-blind trial on 42 non-dialyzed patients with chronic kidney disease showed that vitamin D3 associated with vitamin $\mathrm{K}$ has an additive or a synergistic effect on the decrease of intima-media thickness (Kurnatowska et al., 2015). However, synergistic effect between vitamin D3 and K may only exist at optimal concentrations. Indeed, an observational singlecenter cohort study showed that vitamin D3 supplementation on renal-transplanted patients with vitamin $\mathrm{K}$ deficiency induced increased mortality and graft failures (van Ballegooijen et al., 2019). Many more trials are currently being led as one can see on web sites for registered trials ${ }^{1,2}$.

Similarly, interactions between calcitriol and vitamin E were observed and particularly to mediate cellular antiproliferative effects. The association of low doses of calcitriol and vitamin E succinate has been reported to have additive effects on the inhibition of human prostatic cancer cells LNCaP proliferation through the stimulation of VDR expression, without adverse effect on calcemia (Yin et al., 2009). An another study led on a rat model showed that vitamin $\mathrm{D}$ and $\mathrm{E}$ deficiencies have synergistic

\footnotetext{
${ }^{1}$ www.clinicaltrials.gov

${ }^{2}$ www.clinicaltrialsregister.eu
} 
effects on rickets development (Sergeev et al., 1987). However, the additive or synergistic mechanism of this association is still unclear and requires further study.

In addition, a synergistic effect of vitamin D3 and A, which is a retinoic acid precursor, has been reported in various cellular models (breast, prostate, colon, and leukemia) but also in mycobacteria (Guilland, 2011; Greenstein et al., 2012). These effects could be linked to the dimerization between the VDR and RXR, which creates an interconnection between the calcitriol and retinoic acid cellular pathways. Indeed, retinoic acid could modulate the vitamin D3 effects. Several studies pointed out an antagonism or additive/synergetic effects between both vitamins. For instance, Kane et al. (1996) showed an inhibition by retinoic acid of the antiproliferative effect of calcitriol on colon cancer cells. However, several studies reported a synergistic effect. In vitro, on human prostatic cancer cells LNCaP, Blutt et al. (1997) suggested that calcitriol and retinoic acid act synergistically to inhibit the growth of cancer cells and cause accumulation of cells in G1. Carlberg et al. (1993) showed that in drosophila SL-3 cells transfected with mouse VDR or RXR genes, the VDRE was synergistically activated by RXR and VDR, but only in the presence of both factors. Regarding the nervous system, the RXR has been shown to be involved in the differentiation of oligodendrocyte progenitors into mature oligodendrocytes (de la Fuente et al., 2015), and also in neuronal differentiation (Mounier et al., 2015). It is well known that retinoic acid plays a major role during the embryological development of the central nervous system, leading the neuroectoderm to caudalize itself. On the other hand, calcitriol also plays a role in neuro-embryogenesis (Shirazi et al., 2015). Thus, it is conceivable that a synergistic interconnection between retinoic acid and calcitriol exists during nervous system development. All of the interactions between vitamin $\mathrm{D}$ and other fat-soluble vitamins presented above show that this field is quite large and matter for further explorations in the nervous system.

\section{Cardiovascular Effects and Systemic Interactions of Vitamin D3}

Vitamin D3 has been suspected to play a role in cardioprotection. Indeed, VDR-deficient mice showed adverse cardiac remodeling and hypertension (Meems et al., 2011). However, in an observational, prospective and population-based cohort study, calcitriol or calcidiol plasmatic levels have failed in predicting higher risk of heart failure (Meems et al., 2016). Thus, further studies are required to investigate strong evidence-based relationship between Vitamin D3 and heart failure. On the other hand, 1,25- $(\mathrm{OH})_{2}$-vitamin D3 may also induce adverse effects in humans. Another observational, prospective and populationbased cohort study demonstrated that plasma calcitriol levels are associated with an elevated risk of hypertension (van Ballegooijen et al., 2015). Intriguingly and unexpectedly, cholecalciferol plasma levels are inversely associated with hypertension. However, calcitriol supplementation was shown to cause renal calcification in an experimental laboratory study led on a suckling rat model (Dostal et al., 1984), which is confirmed by the fact that, in humans, cholecalciferol supplementation is associated with kidney-stone formation, linked to increased hypercalciuria (Letavernier and Daudon, 2018).

\section{ROLES OF VITAMIN D3 IN THE NERVOUS SYSTEM}

As reported above and in Table 1, data suggest that calcitriol has a role in the nervous system and that vitamin D3 acts as a neurosteroid (Emmanuel et al., 2002; Melcangi and Panzica, 2009). However, the role, if any, of the calcitriol in the peripheral nervous system needs to be more precisely defined.

\section{Vitamin D3 and Cell Differentiation}

We further investigate the role of calcitriol in nervous system development, particularly neuronal cell differentiation, by focusing on the various actors known to be regulated by calcitriol, such as the Wnt signaling pathway, Sonic hedgehog (Shh), and Klotho, as well as on the putative role of progesterone to stimulate the effect of calcitriol in differentiation.

\section{Wnt Proteins}

Wnt proteins are cysteine-rich glycosylated proteins that control multiple processes involving neuronal development, angiogenesis, immunity, tumorigenesis, fibrosis, and stem-cell proliferation (Maiese, 2015). Wnt is also involved in nervous system development, particularly as a positive regulator of the myelination process, by promoting myelin gene expression. Tawk et al. (2011) demonstrated that the inactivation of Wnt components in vitro in mouse Schwann cells leads to severe dysmyelination and the inhibition of myelin gene expression. Calcitriol has been shown to disrupt $\mathrm{Wnt} / \beta$-catenin signaling through multiple mechanisms. Hlaing et al. (2014) reported that vitamin D promotes cardiac differentiation through the negative modulation of the canonical Wnt signaling pathway and upregulation of the expression of Wnt11, in vitro culture of H9c2 rat embryonic myocardium cells. Lim et al. (2014) found that decreased expression of the VDR is associated with decreased expression of $\mathrm{Wnt} / \beta$-catenin signals in follicle dermal papilla cells, inhibiting the proliferation, and differentiation of hair follicles and epidermal cells.

\section{The Shh Pathway}

Sonic hedgehog signaling is involved in the induction of neuronal populations in the central and peripheral nervous systems and neural stem-cell proliferation (Choudhry et al., 2014). In a recent study in an embryonic carcinoma mice cell line (P19EC), Vuong et al. (2017) clearly showed that Shh signaling regulates neuronal differentiation and neurite growth. In an experimental study using VDR-deficient mice, Teichert et al. (2011) reported that VDR-null animals overexpress Shh in keratinocytes and that such overexpression is downregulated by $1,25-(\mathrm{OH})_{2}$-vitamin D3. These results were supported by Dormoy et al. (2012) who showed that vitamin D decreases cell proliferation and increases cell death by inhibiting the Shh pathway in human renal carcinoma cells. Although the Wnt/ $\beta$-catenin pathway and Shh 


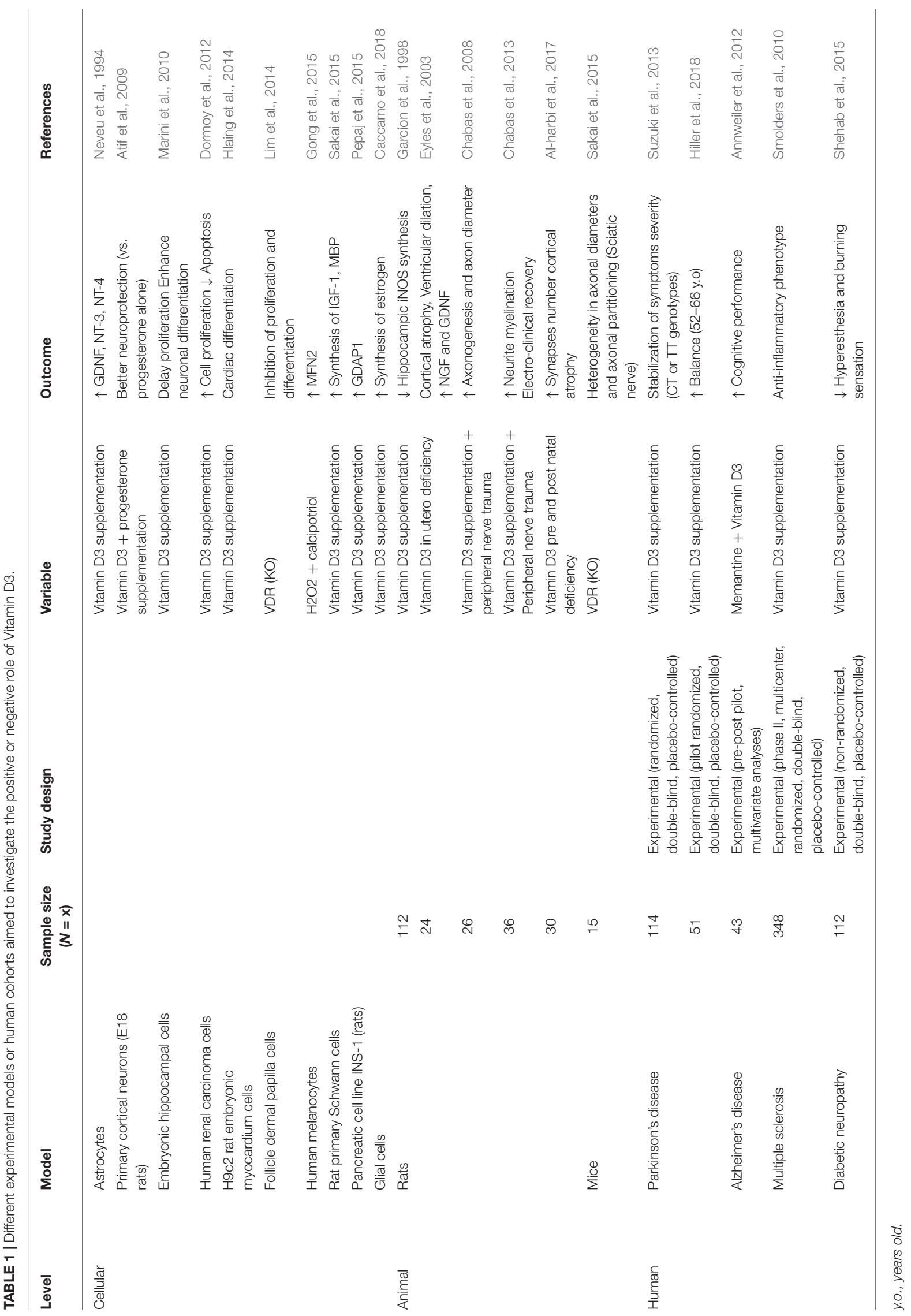


signaling are well known to regulate the progression of spinalcord progenitors and promote neurogenesis, particularly spinal motor-neuron development, the role of vitamin $\mathrm{D}$ in motorneuron cell differentiation needs to be investigated. Further studies are necessary to clearly elucidate the role of vitamin $\mathrm{D}$ in neuronal cell differentiation through this pathway (Appel and Eisen, 2003; Andersson et al., 2013).

\section{The Klotho Pathway}

Several studies have reported a complex interaction between calcitriol activity and the Klotho gene. The Klotho gene was discovered in 1997 when mice in which this gene was silenced developed pre-mature aging syndrome (Kuro-o et al., 1997). It is highly expressed in the brain and, to a lesser extent, in other organs (Kuro-o et al., 1997). The choroid plexus is a site of abundant Klotho expression. It is well known that several factors, including phosphate and vitamin $\mathrm{D}$, can regulate the production of Klotho, as well as fibroblast growth factor 23 (FGF23). Kalueff and Tuohimaa (2007) suggested that Klotho expression is upregulated by calcitriol in a murine model. FGF23 was identified as a phosphaturic hormone which is produced in the bone and controls mineral homeostasis by the regulation of calcitriol (White et al., 2000). FGF23 is known to suppress vitamin $\mathrm{D}$ hormone production in the kidney by downregulating renal $1 \alpha$ hydroxylase expression, thereby suppressing the production of calcitriol (Erben, 2016). However, little is known about the functional role of Klotho and FGF23 in the central nervous system. Although Anour et al. (2012) reported that Klotho/VDR complex mutant mice do not show obvious behavioral abnormalities, mice with a non-functioning vitamin $\mathrm{D}$ receptor fully restored the premature aging phenotype in Klotho deficient mice. These mice produce excessive amounts of calcitriol due to the lack of the suppressive effect of FGF23 on $1 \alpha$ hydroxylase expression. Thus, the premature aging phenotype in Klotho deficient mice could be caused by intoxication with the vitamin $\mathrm{D}$ hormone, leading to severe hypercalcemia and hyperphosphatemia and subsequent organ damage (Erben, 2016). Anamizu et al. (2005) reported that Klotho insufficiency causes atrophy and dysfunction of spinal large anterior horn cells in a mouse model deficient for Klotho, suggesting its putative role in neuronal-cell differentiation, potentially promoted by vitamin $\mathrm{D}$.

\section{Progesterone}

Marini et al. (2010) reported that vitamin D delays cell proliferation and induces cell differentiation, with modification of soma lengthening and the formation of axons and dendrites in a study using embryonic hippocampal cells. Various observations have also shown that progesterone treatment may be beneficial in several brain-injury models (Sayeed and Stein, 2009). Although progesterone treatment of animals submitted to traumatic brain injury was shown ineffective, treatment with this steroid was effective if calcitriol was simultaneously given (Cekic et al., 2009). In addition, results show that progesterone combined with vitamin D promotes better neuroprotection against excitotoxicity than progesterone alone in an E18 rat primary cortical neurons pretreated with various concentrations of progesterone and vitamin D separately or in combination for $24 \mathrm{~h}$ (Atif et al., 2009). Moreover, given the role of progesterone in myelin formation in the peripheral nervous system, it could be informative to further study whether calcitriol can synergize with progesterone activity in the myelination process in the peripheral nervous system (Zárate et al., 2017). Finally, calcitriol has been shown to increase local estrogen production in glial cells through the upregulation of the aromatase enzyme (Caccamo et al., 2018). Given the role of estrogens on neuroprotection and neuronal DNA repair enzymes in rodents (Zárate et al., 2017), we suggest that calcitriol can exert a neuroprotective effect through the estrogen pathway.

\section{Neuronal Cell Differentiation}

Calcitriol could be used to potentiate neuronal-cell differentiation in progenitor cell lines. Indeed, Agholme et al. (2010) reported that in vitro pre-treatment of SH-SY5Y cells, human neuroblastoma cells, with retinoic acid, followed by culturing on an extracellular matrix in combination with a cocktail of neurotrophic factors associated with vitamin D3 treatment, generated sustainable cells with an unambiguous resemblance to adult neurons. Preliminary experiments conducted in our lab on neuronal cells with various concentrations of calcitriol suggest that calcitriol can induce motor-neuron differentiation but without any effect on proliferation. Confirmatory studies are under way.

\section{Axonal Homogeneity}

As mentioned, vitamin D3 and its metabolites also play a role in neurites integrity. The VDR KO mouse model described by Sakai et al. (2015) underlined the involvement of calcitriol and the VDR in axonal homogeneity, integrity, and maintenance of neuromuscular junctions. Indeed, the analysis of transversal sections of sciatic nerves from VDR-deficient mice showed heterogeneity of the axonal diameters and axonal repartitioning among the nerves (Sakai et al., 2015). In addition, they showed in a rat primary Schwann cells model, that calcitriol upregulates the expression of IGF-1, a myelin basic protein which is a myotrophic and neurotrophic factor. Gao et al. (1999) showed that IGF-I deficient mice exhibit reduced peripheral nerve conduction velocities and smaller axonal diameters. They also demonstrated that IGF-1 plays a key role in the growth and development of the peripheral nervous system and that systemic IGF-1 treatment can enhance nerve function in these adults deficient mice (Gao et al., 1999).

\section{Anti-oxidative Activity}

Anti-oxidative stress activity has been reported for calcitriol in the central nervous system (Garcion et al., 1998). Injections of lipopolysaccharide were performed in vivo in rat hippocampus to induce the synthesis of induced nitric oxide synthase (iNOS), which is partially involved in oxidative stress in the brain and vasodilation through nitrogen monoxide (NO) generation. This study showed significant inhibition of iNOS synthesis in the group with calcitriol treatment, suggesting a putative role of calcitriol against oxidative stress and vasodilation in the brain. Furthermore, the authors also showed that vitamin $\mathrm{D}$ increased the intracellular levels of glutathione, the major 
intracellular redox buffer, in primary cultures of newborn-rat astrocytes (Garcion et al., 1999). Although oxidative stress and inflammatory processes appear to promote calcium dysregulation with age, several endogenous steroid hormones, including vitamin $\mathrm{D}$, estrogen, and insulin may counteract, at least partially, these effects (Frazier et al., 2017).

\section{Renin-Angiotensin System and Vitamin D}

Several studies have shown an interaction between the reninangiotensin system (RAS) and calcitriol regulation. Rammos et al. (2008) showed that vitamin D downregulates renin and vitamin D deficiency upregulates the RAS in a murine model. These results have been supported by several studies showing that renin expression and plasma angiotensin II production are elevated in VDR-null mice, leading to hypertension and cardiac hypertrophy, whereas $1,25-(\mathrm{OH})_{2}$-vitamin D3 treatment suppresses renin expression (Li et al., 2002; Yang et al., 2018). In addition, 1,25-(OH $)_{2}$-vitamin D3 administration corrects hypertension induced by activation of the RAS in a model of 1-alpha-hydroxylase-deficient mice (Zhang et al., 2015). These renal abnormalities were also observed in a rat model of diabetes in which calcitriol blocks RAS activation (Deng et al., 2016). These interactions have also been observed in humans. In a large cohort, Tomaschitz et al. (2010) reported that serum 1,25$(\mathrm{OH})_{2}$-vitamin D3 concentrations were inversely correlated with plasma renin activity and angiotensin II levels. Calcitriol can also regulate the RAS in organs other than the kidney and perhaps in peripheral nerves, where angiotensin receptors have already been described. Indeed, Bessaguet et al. (2017) in a recent study showed that candesartan, a blocker of AT1 and AT2 receptors, prevents this type of neuropathy by acting on the RAS, in mice exhibiting sensory small fiber injury induced by resiniferatoxin treatment. They concluded that the AT2R may have neuroprotective effects (Bessaguet et al., 2017). Given the previous observation in kidney, the role of vitamin $\mathrm{D}$ in this pathway needs to be investigated to clarify its role in the regulation of the RAS, particularly its interaction with oxidative stress, well known to interact with the RAS (Luo et al., 2015). RAS hyperactivity associated with progression to renal damage and the modulation of calcitriol production is found in chronic kidney diseases (Santos et al., 2012).

Relationships between Vitamin D3, both cholecalciferol and calcitriol, and renal function have been extensively studied. First, renal injuries induce a decline in the glomerular filtration rate (eGFR), often associated with a reduction of 1-alphahydroxylase enzyme activity in kidney, inducing a decrease of plasma 1,25-(OH $)_{2}$-vitamin D3 levels. Such low levels in the blood result in several downstream effects, such as secondary hyperparathyroidism and the modification of bone homeostasis, requiring treatment with $1,25-(\mathrm{OH})_{2}$-vitamin $\mathrm{D} 3$ or one of its analogs in human patients with chronic kidney diseases (Bhan, 2014). As shown by a cross-sectional study integrating results of 5 cohort studies and clinical trials, it seems that low eGFR is also associated with important decrease in Vitamin D3 catabolism (de Boer et al., 2014). Second, Vitamin D deficiency impacts in a different manner the general population and renal transplanted patients. Indeed, as shown by a prospective population-based cohort study, it seems that low calcitriol and low cholecalciferol plasma levels are not associated with decreased eGFR in the general population (Keyzer et al., 2015a). On the contrary, a prospective observational single-center cohort study in stable renal transplanted patients, showed that low 25-OH-vitamin D3 $(<12 \mathrm{ng} / \mathrm{mL})$ is associated with a rapid decline in eGFR (Keyzer et al., 2015b). Interestingly, it seems that vitamin D3 might be not "useful" to normal persons but might have an important positive effect in kidney transplanted persons. This might also be the case for people with peripheral neuropathies.

\section{VITAMIN D3 IN NEUROLOGICAL DISORDERS}

It is commonly accepted that a large proportion of the population in developed countries exhibit insufficient 25-OH-vitamin D3 concentrations in the blood (Singh and Bonham, 2014). Low levels of 25-OH-vitamin D3 are associated with an increased risk of all-cause mortality (Gröber et al., 2015). Although the major sites of action of calcitriol in calcium homeostasis are the bones, kidneys, intestine, and parathyroid gland (Issa et al., 1998), the nervous system may also be involved, particularly in myelinating areas. Various associations have been reported between vitamin D status and brain diseases, such as epilepsy. 25-OH-vitamin D3 supplementation results in improved seizure control in patients with pharmaco-resistant epilepsy (Holló et al., 2012; Miratashi et al., 2017). In 2013, Zhao et al. reported a correlation between 25-OH-vitamin D3 deficiency and the prevalence of Alzheimer's and Parkinson's diseases (Oudshoorn et al., 2008; Zhao et al., 2013). In addition, a study in the United States reported a higher prevalence of dementia among participants with 25-OH-vitamin D3 deficiency (Buell et al., 2010). Kalueff and Tuohimaa (2007) reported the importance of vitamin D/VDR bioactivation in brain neurons, glial cells, brain macrophages, the spinal cord, and the peripheral nervous system, with putative autocrine or paracrine activity.

\section{Brain and Central Nervous-System Disorders}

In the nervous system, vitamin D is involved in calcium trafficking, the redox status, and induction of the synthesis of synaptic structural proteins, neurotrophic factors, and deficient neurotransmitters (Mpandzou et al., 2016). Several results underline the impact of $25-\mathrm{OH}$-vitamin D3 deficiency as a promoting factor in various neurodegenerative diseases, such as amyotrophic lateral sclerosis and Parkinson's and Alzheimer's diseases (Evatt, 2010; Knekt et al., 2010; Mpandzou et al., 2016). The role of calcium in neurodegenerative disorders has been further studied over the last several years (Frazier et al., 2017). In humans, vitamin $\mathrm{D}$ deficiency has long been known to be accompanied by irritability, anxiety, depression, psychoses, and defects in mental development (Kalueff and Tuohimaa, 2007). Calcitriol deficiency is also associated with poor cognitive function in human adults, as well as in children, and could also affect brain development (Wilkins et al., 2006; Lee et al., 2009; Llewellyn et al., 2011). Eyles et al. (2003) demonstrated that rats 
born to vitamin D3-deficient mothers had profound alterations of the brain at birth. Changes in brain structure and a reduction in brain content of nerve-growth factor (NGF) and glial cell-derived neurotrophic factor (GDNF) suggest that low maternal vitamin D3 levels affect the developing brain (Eyles et al., 2003). These results were supported by an experimental study in a rat model with a combined prenatal and postnatal vitamin D3-deficiency (Al-harbi et al., 2017). Al-harbi et al. (2017) reported that this deficiency promoted a decrease in the number of synapses in the molecular layer of the hippocampus, associated with a reduction of cortical thickness.

Astrocytes, which are VDR expressing cells, are important immune cells and contribute to inflammation during neurological disorders. Jiao et al. (2017) reported that lipopolysaccharide-stimulated neuroinflammation in astrocytes could enhance the expression of the VDR and Cyp27B1. In contrast, vitamin D suppressed the expression of proinflammatory cytokines, such as tumor necrosis factor- $\alpha$, interleukin-1 $\beta$, and TLR4 in vivo. These results support a function of reactive astrocytes in stimulating the inflammatory response in neurodegeneration and brain injury and a putative role of vitamin D (Jiao et al., 2017).

Mascarenhas et al. reported an association between severe hypovitaminosis D and persistent, non-specific musculoskeletal pain in humans (Plotnikoff and Quigley, 2003; Mascarenhas and Mobarhan, 2004). Serum vitamin D levels have been inversely correlated with painful manifestations and associated with neuromuscular disorders, which can lead to increased pain sensitivity. Thus, vitamin D3 may also be involved in nociceptive sensitivity (de Oliveira et al., 2017). 1,25-( $\mathrm{OH})_{2}$-vitamin D3 may also upregulate the expression of neurotrophic factors, such as GDNF in C6 glioma cells (Naveilhan et al., 1996), NT-3, or NT4 in rat astrocytes (Neveu et al., 1994), TGFß in neuroblastoma cells (Veenstra et al., 1997), and NGF in the central (Brown et al., 2003; Gezen-Ak et al., 2011) and peripheral nervous systems (Cornet et al., 1998).

Interventional studies of vitamin D3 supplementation for various central nervous system (CNS) diseases have shown promising results. In a randomized double-blind placebo-controlled trial in patients with Parkinson FokI CT and TT genotypes, 12 months of 1,200 UI/day vitamin D3 supplementation resulted in stabilization of the severity (Suzuki et al., 2013). Another randomized double-blind controlled study that assessed 4 months of vitamin D3 supplementation (10.000 UI/day) also showed improvements in balance only in 52- to 66-year-old patients with Parkinson's disease (Hiller et al., 2018). In a single-center trial in patients with Alzheimer's disease, co-administration of memantine with vitamin D3 (400-1000 UI/day or 100,000-200,000 UI/month) for 6 months resulted in a significant and synergistic effect on global cognitive performance (Annweiler et al., 2012). A similar protocol with memantine and vitamin D3 (100,000 UI/month) for 6 months is currently being tested in a single-center double-blind randomized placebocontrolled superiority trial to study its impact on the cognitive performance of patients with Alzheimer's disease and similar disorders (Annweiler et al., 2011). Finally, in an observational retrospective study, 2,000 UI/day vitamin D3 supplementation for 9 months showed no significant adverse events and appeared to have beneficial effects for patients with amyotrophic lateral sclerosis. However, given the low number of patients included (37), further studies are necessary (Karam et al., 2013).

\section{Demyelinating Diseases}

In multiple sclerosis, a demyelinating disease of the central nervous system, environmental factors may contribute to the onset of the disease, in addition to a genetic component. Poor exposure to sun light, resulting in reduced production of vitamin D3 in the skin, is thought to be a risk factor for multiple sclerosis. An association of vitamin D levels with multiple sclerosis was determined in a case control study, which showed an inverse relationship between serum 25-OH-vitamin D3 levels and the prevalence of multiple sclerosis (Pandit et al., 2013). Moreover, low 25-OH-vitamin D3 levels at birth could increase the risk of developing multiple sclerosis, as shown in a recent case-control study (Munger et al., 2016). In addition, vitamin D3 supplementation is increasingly recommended to patients with multiple sclerosis (Nystad et al., 2014). Interventional studies have also been conducted on patients with multiple sclerosis to study the impact of vitamin D3 supplementation. In an interventional single group trial, high doses of vitamin D3 (20,000 UI/day) given to patients with relapsing remitting multiple sclerosis for 12 weeks showed a shift from a pro-inflammatory to an antiinflammatory profile (higher proportion of $\mathrm{IL}-10^{+} \mathrm{CD} 4^{+}$and fewer TH1/TH2 cells) without hypercalcemia or hypercalciuria (Smolders et al., 2010). A phase I/II dose-escalation trial studying the safety of high-dose vitamin D3 supplementation $(40,000 \mathrm{UI} /$ day for 28 weeks, then 10,000 UI/day for 12 weeks and no supplementation for 12 weeks), associated with calcium supplementation $(1,200 \mathrm{mg} /$ day for 42 weeks), confirmed no significant adverse events (Burton et al., 2010). Other interventional studies for vitamin D3 supplementation in patients with multiple sclerosis are currently ongoing (Smolders et al., 2011; Dörr et al., 2012; Bhargava et al., 2014).

In a rodent model of experimental autoimmune encephalomyelitis (EAE), animals immunized against central nervous system proteins, such as myelin-basic protein, develop a paralytic disease that mimics multiple sclerosis. High doses of calcitriol have been shown to prolong survival and improve demyelination scores in the central nervous system relative to those of untreated rodents (Issa et al., 1998; Shirazi et al., 2017). Sakai et al. (2015) showed that calcitriol is essential for the synthesis of myelin basic protein, which is a main component of myelin. Indeed, rat primary Schwann cells treated with calcitriol showed increased production of myelin basic protein, suggesting calcitriol involvement in protein remyelination. Moreover, the effect of high doses of calcitriol on remyelination was investigated in C57B1/6 mice, previously treated with cuprizone, which induces oligodendrocyte apoptosis and subsequent myelin disruption. Calcitriol was able to promote the regenerative process by stimulating oligodendrocyte maturation and astrocyte activation, with a significant increase in 
myelination (Nystad et al., 2014). Both studies suggest an active role of calcitriol in myelination in the central and peripheral nervous systems.

\section{Peripheral Neuropathies}

Calcitriol coordinates the biosynthesis of neurotransmitters in the central nervous system, which regulate cardiovascular autonomic function and may explain its putative role in the development of cardiovascular autonomic neuropathy (Dimova et al., 2017). In addition, Chabas et al. (2008) showed that vitamin D2 (ergocalciferol: a compound produced by yeast with effects similar to those of vitamin D3) has positive effects in vivo at a dose of $100 \mathrm{IU} / \mathrm{kg} /$ day in a rat model of peripheral nerve trauma. At the end of treatment, they observed a significant increase in axonogenesis and axon diameter, improving the response of sensory neurons (Chabas et al., 2008). In 2013, the same authors showed that vitamin D3 is beneficial at a dose of $500 \mathrm{IU} / \mathrm{kg} /$ day in a rat model of peripheral nerve trauma, inducing significant locomotor and electrophysiological recovery. The authors also demonstrated that 25-OH-vitamin D3 increases the number of preserved or newly formed axons in the proximal end, the mean axon diameter in the distal end, and neurite myelination in both the distal and proximal ends (Chabas et al., 2013). In an observational prospective open case-control study with 70 patients undergoing paclitaxel chemotherapy, Grim et al. (2017) reported that estimated vitamin D levels in the group without chemotherapy-induced peripheral neuropathy (CIPN) were $38.2(24.95,47.63) \mathrm{nmol} / \mathrm{L}$, whereas it was $25.6(19.7,32.55)$ $\mathrm{nmol} / \mathrm{L}$ in the group with CIPN. Numerous reports have linked vitamin $\mathrm{D}$ deficiency to an increased risk of diabetes mellitus and complications, such as neuropathy (Putz et al., 2013). Indeed, in a prospective clinical cohort study of 69 diabetic patients,
Celikbilek et al. (2015) reported, that serum vitamin D levels were significantly lower in patients with diabetic peripheral neuropathy than in those without. These results were supported by an observational study showing that 25-OH-vitamin D3 levels were significantly lower in the neuropathy patient group of a 96-patient cohort with type 1 diabetes (Ozuguz et al., 2016). In addition, in a case-control study, Alamdari et al. (2015) reported that lower levels of circulating 25-OH-vitamin D3 may contribute to the risk of large-fiber neuropathy in type 2 diabetic subjects, even after adjustment for demographic variables, comorbidities, and diabetes treatment. They suggested that each $1 \mathrm{ng} / \mathrm{mL}$ increase in the concentration of seric 25$\mathrm{OH}$-vitamin D3 correlates with a 2.2 and $3.4 \%$ decrease in the presence and severity of nerve conduction velocity (NCV) impairment, respectively (Alamdari et al., 2015). Putz et al. (2014) suggested that vitamin D supplementation could have beneficial effects on neuropathic pain and may block the progression of neuronal degeneration. These authors also suggested that vitamin D deficiency could promote diabetic plantar ulcers (Putz et al., 2014). In a prospective placebo-controlled trial that included 112 type 2 diabetic patients with diabetic peripheral neuropathy and vitamin D deficiency, Shehab et al. (2015) showed that short-term oral vitamin D supplementation (50,000 UI/week for 8 weeks) improved hyperesthesia and the burning sensation, assessed by the neuropathy symptom score (NSS). However, this supplementation had no effect on the neuropathy disability score (NDS) nor nerve conduction study (NCS) (Shehab et al., 2015).

Diabetic neuropathy is associated with decreased NGF expression in human diabetic nerves (Anand et al., 1996) and vitamin D3 is also known to induce NGF synthesis in human cell lines (Fukuoka et al., 2001; Shehab et al., 2015). Thus, the observed improvement in diabetic neuropathy may be mediated

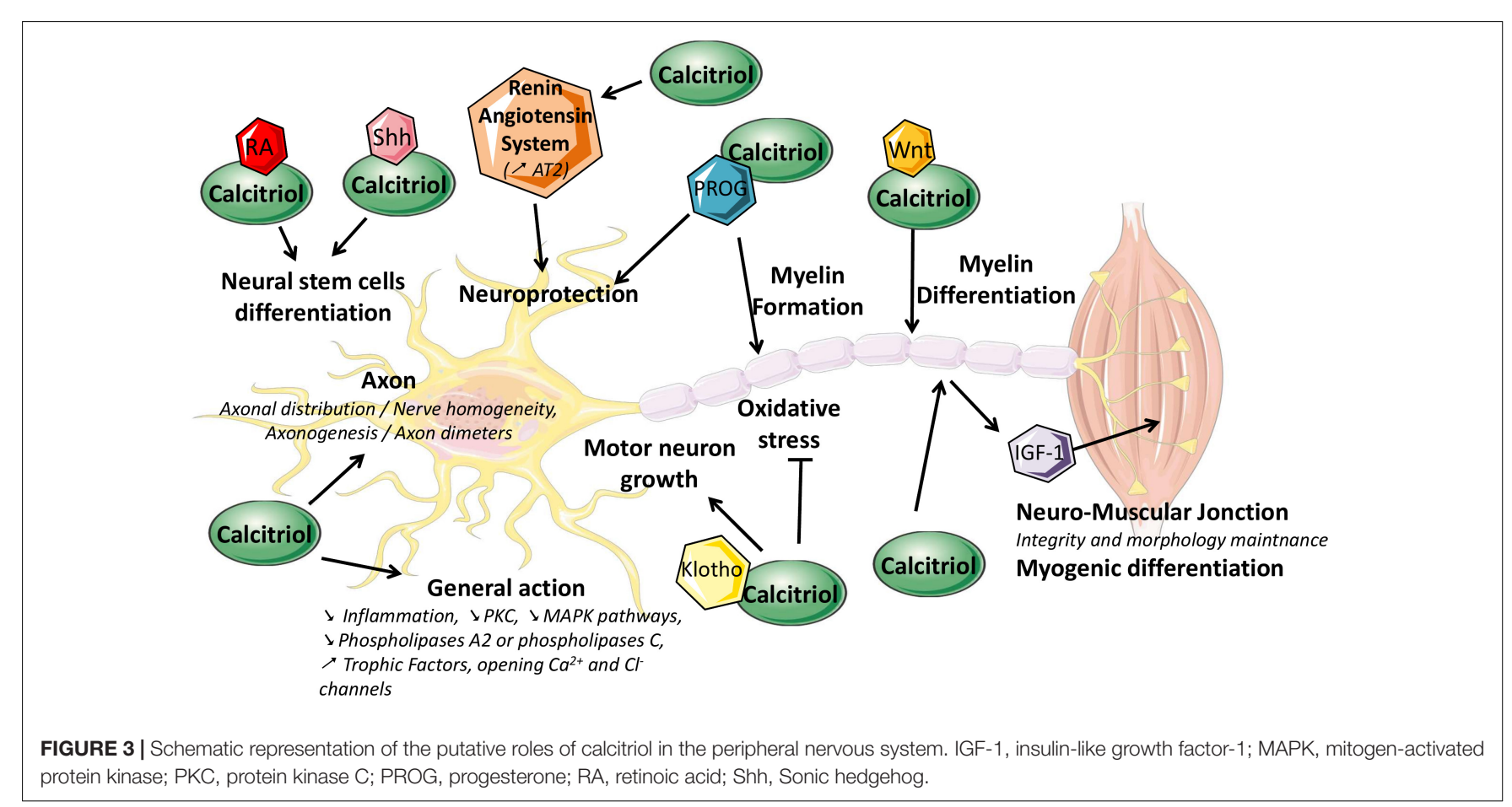


through the upregulation of NGF. Recently, in an experimental randomized clinical trial on 81 women suffering from diabetic neuropathy, Nadi et al. (2017) showed that exercise combined with vitamin $\mathrm{D}$ supplementation decreases the complications of diabetic neuropathy. In addition, a case-report study with one Type-1 patient suffering from diabetic neuropathy, mentioned an improvement after correction of his vitamin D3 deficiency following supplementation of 50,000 UI/week for 4 weeks (Bell, 2012). On the other hand, an interventional randomized doubleblind placebo-controlled trial in non-vitamin D-deficient patients with Type 2 diabetes, showed that vitamin D3 supplementation of 50,000 UI/week for 6 months provided no improvement of diabetic neuropathy (Westra et al., 2016). Placebo-controlled multi-centric studies are required to assess the role of vitamin D3 supplementation on diabetic neuropathies (Valensi et al., 2005). As previously reported, the number of studies that have investigated the role of vitamin $\mathrm{D}$ in the treatment of neuropathies is still limited, mostly to diabetic neuropathy.

\section{Charcot-Marie-Tooth Disease}

Charcot-Marie-Tooth (CMT) disease is the most common form of hereditary motor and sensory neuropathy. Caused by either axonal or demyelinating alterations. More than 90 mutated genes are involved in the development of this neuropathic disease. The observed phenotype is variable but often consists of a progressive distal motor deficiency, foot deformities, or muscular atrophy (Vallat et al., 2007).

Mutations of the ganglioside-induced differentiationassociated protein 1 (GDAP1) gene cause autosomal dominant and autosomal recessive CMT diseases, with more than 40 different pathogenic mutations. Pepaj et al. (2015) used a proteomic approach to show that 1,25-dihydroxyvitamin D3 treatment induces overexpression of GDAP1 in a rat pancreatic beta-1 cell line. Thus, 1,25-vitamin D3 could potentially play a role in CMT, through the up-regulation of the GDAP1 gene. Further studies are required to assess the impact of 1,25dihydroxyvitamin D3 supplementation on the expression of the GDAP1 gene in CMT patients and its clinical impact.

Moreover, another form of CMT disease, type $2 \mathrm{~A}$, is caused by mutations in the mitofusin-2 (MFN2) gene, which is physiologically involved in the fusion/fission of mitochondria. Preclinical studies conducted on neurons from a CMT2A mouse model showed that an MFN2 agonist could normalize mitochondrial trafficking and mobility along axons (GezenAk et al., 2011). Furthermore, Gong et al. (2015) showed that treatment of human melanocytes with $0.05 \% \mathrm{H}_{2} \mathrm{O}_{2}$ and calcipotriol (which is a structural analog of calcitriol) at doses varying from 20 to $80 \mathrm{nM}$ upregulated the expression of MFN2. Thus, calcitriol could be an promising candidate in further studies on CMT2A disease.

Calcitriol has been reported to exhibit gene-dependent synergistic or antagonistic effects when co-administered with inhibitors of histone deacetylase (HDAC) (Malinen et al., 2008; Seuter et al., 2013). Interestingly, HDAC6 inhibition has been reported to restore nerve conduction and motor capacity in glycyl-tRNA synthetase (GARS)-mutated murine neuroblastoma cells, a model for CMT Type 2D (Benoy et al., 2018). Thus, if HDAC inhibitors succeed in showing a therapeutic effect in CMT2D, it would be interesting to further study if calcitriol could potentialize therapeutic effects of HDAC inhibitors in CMT2D diseases. To our knowledge, no study has been conducted yet on the impact of vitamin D3 on the progression of CMT disease. This could represent a new field of therapeutic research in CMT disease.

\section{A New Field of Research}

Several questions should be raised to clearly assess the role of calcitriol in the peripheral nervous system. Does calcitriol have an impact on neuronal differentiation (and on axonal trophicity), or does calcitriol act more on Schwann cells myelination, or does calcitriol improve cellular communications between axons and Schwann cells thus improving myelination and nerve conduction velocities? This would imply a cellular, an animal and a human level of experiments.

For instance, at cellular level, neuronal differentiation comparing standard to calcitriol-supplemented cell cultures, may help assess if calcitriol induces or speeds-up neuronal differentiation. This could be performed on cell lines such as SH-SY5Y or on induced pluripotent stem cells (iPSc). Several techniques such as qRT-PCR, Western-blot and immunostaining on PGP9.5, islet, tuj1, HB9 expression, which are markers of neuronal differentiation, could assess an additive or a synergistic effect of vitamin D3 and other fat-soluble vitamins. Moreover, as micro-glial cells can synthetize calcitriol, 3D-cell culture including neuronal and glial cells could be relevant to study micro-environmental regulation of calcitriol synthesis.

At animal level, experiments could also be led on mice or rats with sciatic nerves injuries, physically or chemically induced, to determine if calcitriol has a positive impact on recovery. Numerous animal models exist for both acquired (toxic, diabetic, crush) and hereditary neuropathies (Sereda et al., 1996). Calcitriol would be administered orally or by a local long term delivery mean as done for curcumin for instance (Caillaud et al., 2018). Effects of calcitriol supplementation could be assessed by functional (skillful walking, grip strength, rotarod), histological (g-ratio) and electrophysiological (NCVs) tests. In these conditions, it would be important to check if calcitriol plays a role in the remyelination process and has synergistic effects with another factor as previously reported.

At a human level, as vitamin D3 is frequently given to elders, a prospective interventional study should be planned to monitor the incidence of peripheral neuropathies. Alternatively, as patients receiving a chemotherapy frequently develop neuropathies, a prospective interventional study could be envisioned to prevent those to occur, provided positive results to investigate in animal models.

\section{CONCLUSION}

Basic science data suggest that current knowledge of calcitriol may still be incomplete and that it may play a more important role in peripheral nerve trophicity than previously thought (Figure 3). 
Several preliminary clinical studies tend to show that calcitriol, indeed, plays such a role. Future molecular and cellular studies may show calcitriol supplementation to be a beneficial means to positively influence peripheral nervous system homeostasis by regulating several processes, such as myelin genesis and axonal maintenance.

\section{AUTHOR CONTRIBUTIONS}

PAF and FP wrote a large proportion of the manuscript and searched for references. FM wrote some parts of the

\section{REFERENCES}

Agholme, L., Lindström, T., Kgedal, K., Marcusson, J., and Hallbeck, M. (2010). An in vitro model for neuroscience: differentiation of SH-SY5Y cells into cells with morphological and biochemical characteristics of mature neurons. J. Alzheimers Dis. 20, 1069-1082. doi: 10.3233/JAD-2010-091363

Alamdari, A., Mozafari, R., Tafakhori, A., Faghihi-Kashani, S., Hafezi-Nejad, N., Sheikhbahaei, S., et al. (2015). An inverse association between serum vitamin $D$ levels with the presence and severity of impaired nerve conduction velocity and large fiber peripheral neuropathy in diabetic subjects. Neurol. Sci. 36, 1121-1126. doi: 10.1007/s10072-015-2207-0

Al-harbi, A.-N., Khan, K. M., and Rahman, A. (2017). Developmental vitamin D deficiency affects spatial learning in wistar rats. J. Nutr. 147, 1795-1805. doi: $10.3945 /$ jn.117.249953

Anamizu, Y., Kawaguchi, H., Seichi, A., Yamaguchi, S., Kawakami, E., Kanda, N., et al. (2005). Klotho insufficiency causes decrease of ribosomal RNA gene transcription activity, cytoplasmic RNA and rough ER in the spinal anterior horn cells. Acta Neuropathol. 109, 457-466. doi: 10.1007/s00401-0040971-7

Anand, P., Terenghi, G., Warner, G., Kopelman, P., Williams-Chestnut, R. E., and Sinicropi, D. V. (1996). The role of endogenous nerve growth factor in human diabetic neuropathy. Nat. Med. 2, 703-707. doi: 10.1038/ nm0696-703

Andersson, E. R., Salto, C., Villaescusa, J. C., Cajanek, L., Yang, S., Bryjova, L., et al. (2013). Wnt5a cooperates with canonical wnts to generate midbrain dopaminergic neurons in vivo and in stem cells. Proc. Natl. Acad. Sci. U.S.A. 110, E602-E610. doi: 10.1073/pnas.1208524110

Annweiler, C., Fantino, B., Parot-Schinkel, E., Thiery, S., Gautier, J., and Beauchet, O. (2011). Alzheimer's disease - input of vitamin D with memantine assay (ADIDEA Trial): study protocol for a randomized controlled trial. Trials 12:230. doi: 10.1186/1745-6215-12-230

Annweiler, C., Herrmann, F. R., Fantino, B., Brugg, B., and Beauchet, O. (2012). Effectiveness of the combination of memantine plus vitamin $\mathrm{D}$ on cognition in patients with alzheimer disease: a pre-post pilot study. Cogn. Behav. Neurol. 25, 121-127. doi: 10.1097/WNN.0b013e31826df647

Anour, R., Andrukhova, O., Ritter, E., Zeitz, U., and Erben, R. G. (2012). Klotho lacks a vitamin $\mathrm{D}$ independent physiological role in glucose homeostasis, bone turnover, and steady-state PTH secretion in vivo. PLoS One 7:e31376. doi: 10.1371/journal.pone. 0031376

Appel, B., and Eisen, J. S. (2003). Retinoids run rampant: multiple roles during spinal cord and motor neuron development. Neuron 40, 461-464. doi: 10.1016/ S0896-6273(03)00688-3

Atif, F., Sayeed, I., Ishrat, T., and Stein, D. G. (2009). Progesterone with vitamin D affords better neuroprotection against excitotoxicity in cultured cortical neurons than progesterone alone. Mol. Med. 15, 328-336. doi: 10.2119/molmed. 2009.00016

Baeke, F., Takiishi, T., Korf, H., Gysemans, C., and Mathieu, C. (2010). Vitamin D: modulator of the immune system. Curr. Opin. Pharmacol. 10, 482-496. doi: $10.1016 /$ j.coph.2010.04.001

Bell, D. S. H. (2012). Reversal of the symptoms of diabetic neuropathy through correction of vitamin D deficiency in a type 1 diabetic patient. Case Rep. Endocrinol. 2012:165056. doi: 10.1155/2012/165056 manuscript and inserted the references. ASL and CD proofread the sections concerning gene regulation and pharmacology. LM, as a neurologist, proofread the clinical part of the manuscript. FF wrote some parts of the manuscript and modified the general structure to make it more readable. FS initiated the work on vitamin $\mathrm{D}$ and proofread the manuscript several times.

\section{FUNDING}

This work was supported by the University of Limoges, Limoges, France and CHU de Limoges, France.

Benoy, V., Van Helleputte, L., Prior, R., D’Ydewalle, C., Haeck, W., Geens, N., et al. (2018). HDAC6 is a therapeutic target in mutant GARS-induced charcot-marietooth disease. Brain 141, 673-687. doi: 10.1093/brain/awx375

Bessaguet, F., Danigo, A., Magy, L., Sturtz, F., Desmoulière, A., and Demiot, C. (2017). Candesartan prevents resiniferatoxin-induced sensory smallfiber neuropathy in mice by promoting angiotensin II-mediated AT2 receptor stimulation. Neuropharmacology 126, 142-150. doi: 10.1016/J. NEUROPHARM.2017.08.039

Bhan, I. (2014). Breaking down the Vitamin D-GFR relationship. Am. J. Kidney Dis. 64, 168-170. doi: 10.1053/j.ajkd.2014.05.004

Bhargava, P., Cassard, S., Steele, S. U., Azevedo, C., Pelletier, D., Sugar, E. A., et al. (2014). The vitamin D to ameliorate multiple sclerosis (VIDAMS) trial: study design for a multicenter, randomized, double-blind controlled trial of vitamin D in multiple sclerosis. Contemp. Clin. Trials 39, 288-293. doi: 10.1016/j.cct. 2014.10.004

Blutt, S. E., Allegretto, E. A., Pike, J. W., and Weigel, N. L. (1997). 1,25Dihydroxyvitamin D3 and 9-Cis-retinoic acid act synergistically to inhibit the growth of LNCaP prostate cells and cause accumulation of cells in G1. Endocrinology 138, 1491-1497. doi: 10.1210/endo.138.4.5063

Brown, J., Bianco, J. I., McGrath, J. J., and Eyles, D. W. (2003). 1,25Dihydroxyvitamin D3 induces nerve growth factor, promotes neurite outgrowth and inhibits mitosis in embryonic rat hippocampal neurons. Neurosci. Lett. 343, 139-143. doi: 10.1016/S0304-3940(03)00303-3

Buell, J. S., Dawson-Hughes, B., Scott, T. M., Weiner, D. E., Dallal, G. E., Qui, W. Q., et al. (2010). 25-Hydroxyvitamin D, dementia, and cerebrovascular pathology in elders receiving home services. Neurology 74, 18-26. doi: 10.1212/WNL. 0b013e3181beecb7

Buitrago, C., Gonzalez Pardo, V., and Boland, R. (2013). Role of VDR in 1 $\alpha, 25-$ dihydroxyvitamin D3-dependent non-genomic activation of MAPKs, Src and Akt in skeletal muscle cells. J. Steroid Biochem. Mol. Biol. 136, 125-130. doi: 10.1016/j.jsbmb.2013.02.013

Burton, J. M., Kimball, S., Vieth, R., Bar-Or, A., Dosch, H.-M., Cheung, R., et al. (2010). A phase I/II dose-escalation trial of vitamin D3 and calcium in multiple sclerosis. Neurology 74, 1852-1859. doi: 10.1212/WNL.0b013e3181e1cec2

Caccamo, D., Ricca, S., Currò, M., and Ientile, R. (2018). Health risks of hypovitaminosis D: a review of new molecular insights. Int. J. Mol. Sci. 19:E892. doi: 10.3390/ijms19030892

Caillaud, M., Chantemargue, B., Richard, L., Vignaud, L., Frédéric, F., Faye, P.-A., et al. (2018). Local low dose curcumin treatment improves functional recovery and remyelination in a rat model of sciatic nerve crush through inhibition of oxidative stress. Neuropharmacology 139, 98-116. doi: 10.1016/j.neuropharm. 2018.07.001

Carlberg, C., Bendik, I., Wyss, A., Meier, E., Sturzenbecker, L. J., Grippo, J. F., et al. (1993). Two nuclear signalling pathways for vitamin D. Nature 361, 657-660. doi: $10.1038 / 361657 \mathrm{a} 0$

Cekic, M., Sayeed, I., and Stein, G. D. (2009). Hormone may be more effective than monotherapy for nervous. Front. Neuroendocrinol. 30, 158-172. doi: 10.1016/j. yfrne.2009.04.002

Celikbilek, A., Yesim Gocmen, A., Tanik, N., Borekci, E., Adam, M., Celikbilek, M., et al. (2015). Decreased serum vitamin D levels are associated with diabetic peripheral neuropathy in a rural area of turkey. Acta Neurol. Belg. 115, 47-52. doi: $10.1007 / \mathrm{s} 13760-014-0304-0$ 
Chabas, D. S., Marqueste, T., Garcia, S., Lavaut, M.-N., Nguyen, C., Legre, R., et al. (2013). Cholecalciferol (Vitamin D3) improves myelination and recovery after nerve injury. PLoS One 8:e65034. doi: 10.1371/journal.pone.0065034

Chabas, O. A., Rao, G., Garcia, S., Lavaut, M.-N., Risso, J.-J., Legre, R., et al. (2008). Vitamin D2 potentiates axon regeneration. J. Neurotrauma 25, 1247-1256. doi: 10.1089/neu.2008.0593

Choudhry, Z., Rikani, A. A., Choudhry, A. M., Tariq, S., Zakaria, F., Asghar, M. W., et al. (2014). Sonic hedgehog signalling pathway: a complex network. Ann. Neurosci. 21, 28-31. doi: 10.5214/ans.0972.7531.210109

Christakos, S., Dhawan, P., Verstuyf, A., Verlinden, L., and Carmeliet, G. (2016). Vitamin D: metabolism, molecular mechanism of action, and pleiotropic effects. Physiol. Rev. 96, 365-408. doi: 10.1152/physrev.00014.2015

Cornet, A., Baudet, C., Neveu, I., Baron-Van Evercooren, A., Brachet, P., and Naveilhan, P. (1998). 1,25-Dihydroxyvitamin D3 regulates the expression of VDR and NGF gene in schwann cells in vitro. J. Neurosci. Res. 53, 742746. doi: 10.1002/(sici)1097-4547(19980915)53\%3A6\%3C742\%3A\%3Aaidjnr11\%3E3.0.co\%3B2-\%23

de Boer, I., Sachs, M. C., Chonchol, M., Himmelfarb, J., Hoofnagle, N. A., Ix, J. H., et al. (2014). Estimated GFR and circulating 24,25-dihydroxyvitamin D3 concentration: a participant-level analysis of 5 cohort studies and clinical trials. Am. J. Kidney Dis. 64, 187-197. doi: 10.1053/j.ajkd.2014.02.015

de la Fuente, A. G., Errea, O., van Wijngaarden, P., Gonzalez, G. A., Kerninon, C., Jarjour, A. A., et al. (2015). Vitamin D receptor-retinoid X receptor heterodimer signaling regulates oligodendrocyte progenitor cell differentiation. J. Cell Biol. 211, 975-985. doi: 10.1083/jcb.201505119

de Oliveira, D. L., Hirotsu, C., Tufik, S., and Levy Andersen, M. (2017). The interfaces between vitamin D, sleep and pain. J. Endocrinol. 234, R23-R36. doi: 10.1530/JOE-16-0514

Deng, X., Cheng, J., and Shen, M. (2016). Vitamin D improves diabetic nephropathy in rats by inhibiting renin and relieving oxidative stress. J. Endocrinol. Investig. 39, 657-666. doi: 10.1007/s40618-015-0414-4

Dimova, R., Tankova, T., and Chakarova, N. (2017). Vitamin D in the spectrum of prediabetes and cardiovascular autonomic dysfunction. J. Nutr. 147, 16071615. doi: 10.3945/jn.117.250209

Dormoy, V., Béraud, C., Lindner, V., Coquard, C., Barthelmebs, M., Brasse, D., et al. (2012). Vitamin D3 triggers antitumor activity through targeting hedgehog signaling in human renal cell carcinoma. Carcinogenesis 33, 2084-2093. doi: $10.1093 /$ carcin/bgs255

Dörr, J., Ohlraun, S., Skarabis, H., and Paul, F. (2012). Efficacy of vitamin D supplementation in multiple sclerosis (EVIDIMS Trial): study protocol for a randomized controlled trial. Trials 13:15. doi: 10.1186/1745-6215-13-15

Dostal, L. A., Toverud, S. U., and Peach, R. (1984). Renal calcification in suckling rats after high doses of calcitriol (1,25-Dihydroxycholecalciferol). Arch. Pathol. Lab. Med. 108, 410-415.

El-Atifi, M., Dreyfus, M., Berger, F., and Wion, D. (2015). Expression of CYP2R1 and VDR in human brain pericytes: the neurovascular vitamin D autocrine/paracrine model. Neuroreport 26, 245-248. doi: 10.1097/WNR. 0000000000000328

Emmanuel, G., Wion-Barbot, N., Montero-Menei, C. N., Berger, F., and Wion, F. (2002). New clues about vitamin D functions in the nervous system. Trends Endocrinol. Metab. 13, 100-105. doi: 10.1016/S1043-2760(01)00547-1

Erben, R. G. (2016). Update on FGF23 and klotho signaling. Mol. Cell. Endocrinol. 432, 56-65. doi: 10.1016/j.mce.2016.05.008

Evatt, M. L. (2010). Beyond vitamin status. Arch. Neurol. 67, 795-797. doi: 10.1001/ archneurol.2010.123

Eyles, D., Brown, J., Mackay-Sim, A., McGrath, J., and Feron, F. (2003). Vitamin D3 and brain development. Neuroscience 118, 641-653. doi: 10.1016/S03064522(03)00040-X

Eyles, D. W., Smith, S., Kinobe, R., Hewison, M., and McGrath, J. J. (2005). Distribution of the vitamin D receptor and 1 alpha-hydroxylase in human brain. J. Chem. Neuroanat. 29, 21-30. doi: 10.1016/j.jchemneu.2004.08.006

Finnes, T. E., Lofthus, C. M., Meyer, H. E., Søgaard, A. J., Tell, G. S., Apalset, E. M., et al. (2016). A combination of low serum concentrations of vitamins K1 and $\mathrm{D}$ is associated with increased risk of hip fractures in elderly norwegians: a NOREPOS study. Osteoporos. Int. 27, 1645-1652. doi: 10.1007/s00198-0153435-0

Frazier, H. N., Maimaiti, S., Anderson, K. L., Brewer, L. D., Gant, J. C., Porter, N. M., et al. (2017). Calcium's role as nuanced modulator of cellular physiology in the brain. Biochem. Biophys. Res. Commun. 483, 981-987. doi: 10.1016/j.bbrc.2016. 08.105

Fukuoka, M., Sakurai, K., Ohta, T., Kiyoki, M., and Katayama, I. (2001). Tacalcitol, an active vitamin D3, induces nerve growth factor production in human epidermal keratinocytes. Skin Pharmacol. Appl. Skin Physiol. 14, 226-233. doi: $10.1159 / 000056351$

Fusaro, M., Giannini, S., Gallieni, M., Noale, M., Tripepi, G., Rossini, M., et al. (2016). Calcimimetic and vitamin D analog use in hemodialyzed patients is associated with increased levels of vitamin $\mathrm{K}$ dependent proteins. Endocrine 51, 333-341. doi: 10.1007/s12020-015-0673-z

Gao, W. Q., Shinsky, N., Ingle, G., Beck, K., Elias, K. A., and Powell-Braxton, L. (1999). IGF-I deficient mice show reduced peripheral nerve conduction velocities and decreased axonal diameters and respond to exogenous IGF-I treatment. J. Neurobiol. 39, 142-152. doi: 10.1002/(sici)1097-4695(199904)39\% 3A1\%3C142\%3A\%3Aaid-neu11\%3E3.0.co\%3B2-h

Garabédian, M. (2000). La vitamine D: les nouvelles fonctions d'une ancienne vitamine. Oleagineux Corps Gras Lipides 7, 271-275. doi: 10.1051/ocl.2000.0271

Garcion, E., Sindji, L., Leblondel, G., Brachet, P., and Darcy, F. (1999). 1,25-Dihydroxyvitamin D3 regulates the synthesis of gamma-glutamyl transpeptidase and glutathione levels in rat primary astrocytes. J. Neurochem. 73, 859-866. doi: 10.1046/j.1471-4159.1999.0730859.x

Garcion, E., Sindji, L., Montero-Menei, C., Andre, C., Brachet, P., and Darcy, F. (1998). Expression of inducible nitric oxide synthase during rat brain inflammation: regulation by 1,25-dihydroxyvitamin D3. Glia 22, 282-294. doi: 10.1002/(sici)1098-1136(199803)22\%3A3\%3C282\%3A\%3Aaidglia7\%3E3.0.co\%3B2-7

Gezen-Ak, D., Dursun, E., and Yilmazer, S. (2011). The effects of vitamin D receptor silencing on the expression of LVSCC-A1C and LVSCC-A1D and the release of NGF in cortical neurons. PLoS One 6:e17553. doi: 10.1371/journal. pone.0017553

Ginde, A. A., Liu, M. C., and Camargo, C. A. (2009). Demographic differences and trends of vitamin D insufficiency in the US population, 1988-2004. Arch. Intern. Med. 169, 626-632. doi: 10.1001/archinternmed.2008.604

Gong, Q., Li, X., Sun, J., Ding, G., Zhou, M., Zhao, W., et al. (2015). The effects of calcipotriol on the dendritic morphology of human melanocytes under oxidative stress and a possible mechanism: is it a mitochondrial protector? J. Dermatol. Sci. 77, 117-124. doi: 10.1016/j.jdermsci.2014.12.006

Greenstein, R. J., Su, L., and Brown, S. T. (2012). Vitamins A \& D inhibit the growth of mycobacteria in radiometric culture. PLoS One 7:e29631. doi: 10. 1371/journal.pone.0029631

Grim, J., Ticha, A., Hyspler, R., Valis, M., and Zadak, Z. (2017). Selected risk nutritional factors for chemotherapy-induced polyneuropathy. Nutrients 9:535. doi: 10.3390/nu9060535

Gröber, U., Reichrath, J., and Holick, M. F. (2015). Live longer with vitamin D? Nutrients 7, 1871-1880. doi: 10.3390/nu7031871

Guilland, J.-C. (2011). Les interactions entre les vitamines A, D, E et K: synergie et/ou compétition. Oléagineux Corps Gras Lipides 18, 59-67. doi: 10.1051/ocl. 2011.0376

Hii, C. S., and Ferrante, A. (2016). The Non-Genomic Actions of Vitamin D. Nutrients 8:135. doi: 10.3390/nu8030135

Hiller, A. L., Murchison, C. F., Lobb, M. B., O'Connor, S., O’Connor, M., and Quinn, J. F. (2018). A randomized, controlled pilot study of the effects of vitamin D supplementation on balance in Parkinson's disease: does age matter? PLoS One 13:e0203637. doi: 10.1371/journal.pone.0203637

Hlaing, S. M., Garcia, L. A., Contreras, J. R., Norris, K. C., Ferrini, M. G., and Artaza, J. N. (2014). 1,25-Vitamin D3 promotes cardiac differentiation through modulation of the WNT signaling pathway. J. Mol. Endocrinol. 53, 303-317. doi: 10.1530/JME-14-0168

Holick, M. F. (2006). High prevalence of vitamin D inadequacy and implications for health. Mayo Clin. Proc. 81, 353-373. doi: 10.4065/81.3.353

Holló, A., Clemens, Z., Kamondi, A., Lakatos, P., and Szucs, A. (2012). Correction of vitamin D deficiency improves seizure control in epilepsy: a pilot study. Epilepsy Behav. 24, 131-133. doi: 10.1016/j.yebeh.2012.03.011

Issa, L. L., Leong, G. M., and Eisman, J. A. (1998). Molecular mechanism of vitamin D receptor action. Inflamm. Res. 47, 451-475. doi: 10.1007/s00011005 0360

Je, S. H., Joo, N. S., Choi, B. H., Kim, K. M., Kim, B. T., Park, S. B., et al. (2011). Vitamin $\mathrm{K}$ supplement along with vitamin $\mathrm{D}$ and calcium reduced serum 
concentration of undercarboxylated osteocalcin while increasing bone mineral density in Korean postmenopausal women over sixty-years-old. J. Korean Med. Sci. 26, 1093-1098. doi: 10.3346/jkms.2011.26.8.1093

Jiao, K. P., Li, S. M., Lv, W. Y., Jv, M. L., and He, H. Y. (2017). Vitamin D3 repressed astrocyte activation following lipopolysaccharide stimulation in vitro and in neonatal rats. Neuroreport 28, 492-497. doi: 10.1097/WNR.0000000000000782

Kalueff, A.-V., and Tuohimaa, P. (2007). Neurosteroid hormone vitamin D and its utility in clinical nutrition. Curr. Opin. Clin. Nutr. Metab. Care 10, 12-19. doi: 10.1097/MCO.0b013e328010ca18

Kane, K. F., Langman, M. J., and Williams, G. R. (1996). Antiproliferative responses to two human colon cancer cell lines to vitamin D3 are differently modified by 9-cis-retinoic acid. Cancer Res. 56, 623-632.

Karam, C., Barrett, M. J., Imperato, T., MacGowan, D. J., and Scelsa, S. (2013). Vitamin D deficiency and its supplementation in patients with amyotrophic lateral sclerosis. J. Clin. Neurosci. 20, 1550-1553. doi: 10.1016/j.jocn.2013.01. 011

Kerner, S. A., Scott, R. A., and Pike, J. W. (1989). Sequence elements in the human osteocalcin gene confer basal activation and inducible response to hormonal vitamin D3. Proc. Natl. Acad. Sci. U.S.A. 86, 4455-4459. doi: 10.1073/pnas.86. 12.4455

Keyzer, C. A., Lambers-Heerspink, H. J., Joosten, M. M., Deetman, P. E., Gansevoort, R. T., Navis, G., et al. (2015a). Plasma vitamin D level and change in albuminuria and EGFR according to sodium intake. Clin. J. Am. Soc. Nephrol. 10, 2119-2127. doi: 10.2215/CJN.03830415

Keyzer, C. A., Riphagen, I. J., Joosten, M. M., Navis, G., Muller Kobold, A. C., Kema, I. P., et al. (2015b). Associations of 25(OH) and 1,25(OH)2 Vitamin D with long-term outcomes in stable renal transplant recipients. J. Clin. Endocrinol. Metab. 100, 81-89. doi: 10.1210/jc.2014-3012

Knekt, P., Kilkkinen, A., Rissanen, H., Marniemi, J., Sääksjärvi, K., and Heliövaara, M. (2010). Serum vitamin D and the risk of Parkinson disease. Arch. Neurol. 67, 808-811. doi: 10.1001/archneurol.2010.120

Kumar, R. (1986). The metabolism and mechanism of action of 1,25dihydroxyvitamin D3. Kidney Int. 30, 793-803. doi: 10.1038/ki.1986.258

Kurnatowska, I., Grzelak, P., Masajtis-Zagajewska, A., Kaczmarska, M., Stefańczyk, L., Vermeer, C., et al. (2015). Effect of vitamin K2 on progression of atherosclerosis and vascular calcification in nondialyzed patients with chronic kidney disease stages 3-5. Pol. Arch. Med. Wewn. 125, 631-640. doi: 10.20452/ pamw.3041

Kuro-o, M., Nabeshima, Y. I., Matsumura, Y., Aizawa, H., Kawaguchi, H., Suga, T., et al. (1997). Mutation of the mouse Klotho gene leads to a syndrome resembling ageing. Nature 390, 45-51. doi: 10.1038/36285

Lee, D. M., Tajar, A., Ulubaev, A., Pendleton, N., O’Neill, W. T., O’Connor, B. D., et al. (2009). Association between 25-Hydroxyvitamin D levels and cognitive performance in middle-aged and older European men. J. Neurol. Neurosurg. Psychiatry 80, 722-729. doi: 10.1136/jnnp.2008.165720

Letavernier, E., and Daudon, M. (2018). Vitamin D, hypercalciuria and kidney stones. Nutrients 10:E366. doi: 10.3390/nu10030366

Li, Y. C., Kong, J., Wei, M., Chen, Z.-F., Liu, S. Q., and Cao, L.-P. (2002). 1,25-Dihydroxyvitamin $\mathrm{D}(3)$ is a negative endocrine regulator of the renin-angiotensin system. J. Clin. Investig. 110, 229-238. doi: 10.1172/ JCI15219

Lim, Y. Y., Kim, S. Y., Kim, H. M., Li, K. S., Kim, M. N., Park, K. C., et al. (2014). Potential relationship between the canonical wnt signalling pathway and expression of the vitamin D receptor in alopecia. Clin. Exp. Dermatol. 39, 368-375. doi: 10.1111/ced.12241

Llewellyn, D. J., Lang, I. A., Langa, K. M., Muniz-Terrera, G., Phillips, C. L., Cherubini, A., et al. (2011). Vitamin D and risk of cognitive decline in elderly persons. Obstet. Gynecol. Surv. 66, 354-355. doi: 10.1097/OGX. 0b013e31822c1957

Luo, H., Wang, X., Chen, C., Wang, J., Zou, X., Li, C., et al. (2015). Oxidative stress causes imbalance of renal renin angiotensin system (RAS) components and hypertension in obese zucker rats. J. Am. Heart Assoc. 4:e001559. doi: 10.1161/JAHA.114.001559

Maiese, K. (2015). Novel applications of trophic factors, wnt and wisp for neuronal repair and regeneration in metabolic disease. Neural Regen. Res. 10, 518-528. doi: 10.4103/1673-5374.155427

Malinen, M., Saramäki, A., Ropponen, A., Degenhardt, T., Väisänen, S., and Carlberg, C. (2008). Distinct HDACs regulate the transcriptional response of human cyclin-dependent kinase inhibitor genes to trichostatin A and 1 12,25-dihydroxyvitamin D3. Nucleic Acids Res. 36, 121-132. doi: 10.1093/nar/ gkm913

Marini, F., Bartoccini, E., Cascianelli, G., Voccoli, V., Gioia Baviglia, M., Viola Magni, M., et al. (2010). Effect of 1alpha, 25-dihydroxyvitamin D3 in embryonic hippocampal cells. Hippocampus 20, 696-705. doi: 10.1002/hipo.20670

Mascarenhas, R., and Mobarhan, S. (2004). Hypovitaminosis D-induced pain. Nutr. Rev. 62, 354-359. doi: 10.1111/j.1753-4887.2004.tb00061.x

Matsunaga, S., Ito, H., and Sakou, T. (1999). The effect of vitamin K and D supplementation on ovariectomy-induced bone loss. Calcif. Tissue Int. 65, 285-289. doi: 10.1007/s002239900700

Mayer, O., Seidlerová, J., Wohlfahrt, P., Filipovský, J., Cífková, R., Černá, V., et al. (2017). Synergistic effect of low K and D vitamin status on arterial stiffness in a general population. J. Nutr. Biochem. 46, 83-89. doi: 10.1016/j.jnutbio.2017. 04.010

Meems, L. M., van der Harst, P., van Gilst, W. H., and de Boer, R. A. (2011). Vitamin D biology in heart failure: molecular mechanisms and systematic review. Curr. Drug Targets 12, 29-41. doi: 10.2174/138945011793591554

Meems, L. M. G., Brouwers, F. P., Joosten, M. M., Lambers Heerspink, H. J., de Zeeuw, D., Bakker, S. J., et al. (2016). Plasma calcidiol, calcitriol, and parathyroid hormone and risk of new onset heart failure in a population-based cohort study. ESC Heart Fail. 3, 189-197. doi: 10.1002/ehf2.12089

Melcangi, R. C., and Panzica, G. (2009). Neuroactive steroids: an update of their roles in central and peripheral nervous system. Psychoneuroendocrinology 34(Suppl. 1), S1-S8. doi: 10.1016/j.psyneuen.2009.11.001

Miratashi, Y., Amir, S., Abbasi, M., Masoud, S., and Yazdi, M. (2017). Epilepsy and vitamin D: a comprehensive review of current knowledge. Rev. Neurosci. 28, 185-201. doi: 10.1515/revneuro-2016-0044

Mounier, A., Georgiev, D., Nam, K. N., Fitz, N. F., Castranio, E. L., Wolfe, C. M., et al. (2015). Bexarotene-activated retinoid X receptors regulate neuronal differentiation and dendritic complexity. J. Neurosci. 35, 11862-11876. doi: 10.1523/JNEUROSCI.1001-15.2015

Mpandzou, G., Aït Ben Haddou, E., Regragui, W., Benomar, A., and Yahyaoui, M. (2016). Vitamin D deficiency and its role in neurological conditions: a review. Rev. Neurol. 172, 109-122. doi: 10.1016/j.neurol.2015.11.005

Munger, K. L., Åivo, J., Hongell, K., Soilu-Hänninen, M., Surcel, H.-M., and Ascherio, A. (2016). Vitamin D status during pregnancy and risk of multiple sclerosis in offspring of women in the Finnish maternity cohort. JAMA Neurol. 73, 515-519. doi: 10.1001/jamaneurol.2015.4800

Nadi, M., Marandi, S. M., Esfarjani, F., Saleki, M., and Mohammadi, M. (2017). The comparison between effects of 12 weeks combined training and vitamin D supplement on improvement of sensory-motor neuropathy in type 2 diabetic women. Adv. Biomed. Res. 6:55. doi: 10.4103/2277-9175.205528

Naveilhan, P., Neveu, I., Wion, D., and Brachet, P. (1996). 1,25-Dihydroxyvitamin D3, an inducer of glial cell line-derived neurotrophic factor. Neuroreport 7 , 2171-2175. doi: 10.1097/00001756-199609020-00023

Neveu, I., Naveilhan, P., Baudet, C., Brachet, P., and Metsis, M. (1994). 1,25-Dihydroxyvitamin D3 regulates NT-3, NT-4 but not BDNF MRNA in astrocytes. Neuroreport 6, 124-126. doi: 10.1097/00001756-19941230000032

Nystad, A. E., Wergeland, S., Aksnes, L., Myhr, K. M., Lars, B., and Torkildsen, O. (2014). Effect of high-dose 1.25 dihydroxyvitamin $\mathrm{d} 3$ on remyelination in the cuprizone model. APMIS 122, 1178-1186. doi: 10.1111/apm.12281

Oudshoorn, C., Mattace-Raso, F. U., Van Der Velde, N., Colin, E. M., and Van Der Cammen, T. J. (2008). Higher serum vitamin D3 levels are associated with better cognitive test performance in patients with Alzheimer's disease. Demen. Geriatr. Cogn. Disord. 25, 539-543. doi: 10.1159/000134382

Ozuguz, U., Oruc, S., Ulu, M. S., Demirbas, H., Acay, A., Coker, B., et al. (2016). Does vitamin D have any role in the improvement of diabetic peripheral neuropathy in type 1 diabetic patients? J. Endocrinol. Investig. 39, 1411-1417. doi: 10.1007/s40618-016-0509-6

Pandit, L., Ramagopalan, S. V., Malli, C., D'Cunha, A., Kunder, R., and Shetty, R. (2013). Association of vitamin D and multiple sclerosis in India. Mult. Scler. J. 19, 1592-1596. doi: 10.1177/1352458513482375

Pepaj, M., Bredahl, M. K., Gjerlaugsen, N., Bornstedt, M. E., and Thorsby, P. M. (2015). Discovery of novel vitamin D-regulated proteins in INS-1 cells: a proteomic approach. Diabetes Metab. Res. Rev. 31, 481-491. doi: 10.1002/dmrr. 2629 
Plotnikoff, G. A., and Quigley, J. M. (2003). Prevalence of severe hypovitaminosis D in patients with persistent, nonspecific musculoskeletal pain. Mayo Clin. Proc. 78, 1463-1470. doi: 10.4065/78.12.1463

Price, P. A., Faus, S. A., and Williamson, M. K. (2000). Warfarin-induced artery calcification is accelerated by growth and vitamin D. Arterioscler. Thromb. Vasc. Biol. 20, 317-327. doi: 10.1161/01.atv.20.2.317

Putz, Z., Martos, T., Németh, N., Erzsébet Körei, A., Erzsébet Vági, O., Soma Kempler, M., et al. (2014). Is there an association between diabetic neuropathy and low vitamin D levels? Curr. Diab. Rep. 14:537. doi: 10.1007/s11892-0140537-6

Putz, Z., Martos, T., Németh, N., Erzsébet Körei, A., Szabó, M., Erzsébet Vági, O., et al. (2013). Vitamin D and neuropathy. Orv. Hetil. 154, 2012-2015. doi: 10.1556/OH.2013.29769

Rammos, G., Tseke, P., and Ziakka, S. (2008). Vitamin D, the renin-angiotensin system, and insulin resistance. Int. Urol. Nephrol. 40, 419-426. doi: 10.1007/ s11255-007-9244-4

Rosen, C. J. (2011). Clinical practice. Vitamin D insufficiency. N. Engl. J. Med. 364, 248-254.

Ross, A. C., Manson, J. E., Abrams, S. A., Aloia, J. F., Brannon, P. M., Clinton, S. K., et al. (2011). The 2011 report on dietary reference intakes for calcium and vitamin $\mathrm{d}$ from the institute of medicine: what clinicians need to know. J. Clin. Endocrinol. Metab. 96, 53-58. doi: 10.1210/jc.2010-2704

Sakai, S., Suzuki, M., Tashiro, Y., Tanaka, K., Takeda, S., Aizawa, K., et al. (2015). Vitamin D receptor signaling enhances locomotive ability in mice. J. Bone Miner. Res. 30, 128-136. doi: 10.1002/jbmr.2317

Santos, P. C., Krieger, J. E., and Costa Pereira, A. (2012). Renin-angiotensin system, hypertension, and chronic kidney disease: pharmacogenetic implications. J. Pharmacol. Sci. 120, 77-88. doi: 10.1254/jphs.12r03cr

Sayeed, I., and Stein, D. G. (2009). Progesterone as a neuroprotective factor in traumatic and ischemic brain injury. Prog. Brain Res. 175, 219-237. doi: 10. 1016/S0079-6123(09)17515-5

Sereda, M., Griffiths, I., Pühlhofer, A., Stewart, H., Rossner, M. J., Zimmerman, F., et al. (1996). A transgenic rat model of charcot-marie-tooth disease. Neuron 16, 1049-1060.

Sergeev, I. N., Kha, K. P., Blazheevich, N. V., and Spirichev, V. B. (1987). [Effect of combined vitamin $\mathrm{D}$ and $\mathrm{E}$ deficiencies on calcium metabolism and bone tissue of the rat]. Vopr. Pitan. 1, 39-43.

Seuter, S., Heikkinen, S., and Carlberg, C. (2013). Chromatin acetylation at transcription start sites and vitamin D receptor binding regions relates to effects of $1 \alpha, 25$-dihydroxyvitamin D3 and histone deacetylase inhibitors on gene expression. Nucleic Acids Res. 41, 110-124. doi: 10.1093/nar/ gks959

Shehab, D., Al-Jarallah, K., Abdella, N., Mojiminiyi, O. A., and Al Mohamedy, H. (2015). Prospective evaluation of the effect of short-term oral vitamin D supplementation on peripheral neuropathy in type 2 diabetes mellitus. Med. Princ. Pract. 24, 250-256. doi: 10.1159/000375304

Shirazi, H. A., Rasouli, J., Ciric, B., Rostami, A., and Xian Zhang, G. (2015). 1,25-Dihydroxyvitamin D3 enhances neural stem cell proliferation and oligodendrocyte differentiation. Exp. Mol. Pathol. 98, 240-245. doi: 10.1016/j. yexmp.2015.02.004

Shirazi, H. A., Rasouli, J., Ciric, B., Wei, D., Rostami, A., and Xian Zhang, G. (2017). 1,25-Dihydroxyvitamin D3 suppressed experimental autoimmune encephalomyelitis through both immunomodulation and oligodendrocyte maturation. Exp. Mol. Pathol. 102, 515-521. doi: 10.1016/j.yexmp.2017. 05.015

Singh, G., and Bonham, A. J. (2014). A predictive equation to guide vitamin D replacement dose in patients. J. Am. Board Fam. Med. 27, 495-509. doi: 10.3122/jabfm.2014.04.130306

Smolders, J., Hupperts, R., Barkhof, F., Grimaldi, L. M., Holmoy, T., Killestein, J., et al. (2011). Efficacy of vitamin D3 as add-on therapy in patients with relapsingremitting multiple sclerosis receiving subcutaneous interferon $\beta$-1a: a phase II, multicenter, double-blind, randomized, placebo-controlled trial. J. Neurol. Sci. 311, 44-49. doi: 10.1016/j.jns.2011.04.013

Smolders, J., Peelen, E., Thewissen, M., Cohen Tervaert, J. W., Menheere, P., Hupperts, R., et al. (2010). Safety and T cell modulating effects of high dose vitamin D3 supplementation in multiple sclerosis. PLoS One 5:e15235. doi: 10.1371/journal.pone.0015235
Spanaus, K., and von Eckardstein, A. (2017). Evaluation of two fully automated immunoassay based tests for the measurement of $1 \alpha, 25$-dihydroxyvitamin D in human serum and comparison with LC-MS/MS. Clin. Chem. Lab. Med. 55, 1305-1314. doi: 10.1515/cclm-2016-1074

Stumpf, W. E. (2012). Drugs in the brain - cellular imaging with receptor microscopic autoradiography. Prog. Histochem. Cytochem. 47, 1-26. doi: 10. 1016/j.proghi.2011.12.001

Suzuki, M., Yoshioka, M., Hashimoto, M., Murakami, M., Noya, M., Takahashi, D., et al. (2013). Randomized, double-blind, placebo-controlled trial of vitamin D supplementation in Parkinson disease. Am. J. Clin. Nutr. 97, 1004-1013. doi: $10.3945 /$ ajcn.112.051664

Tawk, M., Makoukji, J., Belle, M., Fonte, C., Trousson, A., Hawkins, T., et al. (2011). Wnt/ -catenin signaling is an essential and direct driver of myelin gene expression and myelinogenesis. J. Neurosci. 31, 3729-3742. doi: 10.1523/ JNEUROSCI.4270-10.2011

Teichert, A. E., Elalieh, H., Elias, P. M., Welsh, J., and Bikle, D. D. A. (2011). Overexpression of hedgehog signaling is associated with epidermal tumor formation in vitamin D receptor null mice arnaud. J. Investig. Dermatol. 131, 2289-2297. doi: 10.1038/jid.2011.196

Tesoriere, L., Bongiorno, A., Pintaudi, A. M., D’Anna, R., D’Arpa, D., and Livrea, M. A. (1996). Synergistic Interactions between Vitamin A and Vitamin $E$ against lipid peroxidation in phosphatidylcholine liposomes. Arch. Biochem. Biophys. 326, 57-63. doi: 10.1006/abbi. 1996.0046

Tomaschitz, A., Pilz, S., Ritz, E., Grammer, T., Drechsler, C., Boehm, B. O., et al. (2010). Independent association between 1,25-dihydroxyvitamin D, 25hydroxyvitamin D and the renin-angiotensin system: the Ludwigshafen risk and cardiovascular health (LURIC) study. Clin. Chim. Acta Int. J. Clin. Chem. 411, 1354-1360. doi: 10.1016/j.cca.2010.05.037

Ushiroyama, T., Ikeda, A., and Ueki, M. (2002). Effect of continuous combined therapy with vitamin $\mathrm{K}(2)$ and vitamin $\mathrm{D}(3)$ on bone mineral density and coagulofibrinolysis function in postmenopausal women. Maturitas 41, 211-221. doi: 10.1016/s0378-5122(01)00275-4

Valensi, P., Le Devehat, C., Richard, J.-L., Farez, C., Khodabandehlou, T., Rosenbloom, R. A., et al. (2005). A multicenter, double-blind, safety study of QR-333 for the treatment of symptomatic diabetic peripheral neuropathy. A preliminary report. J. Diabetes Complications 19, 247-253. doi: 10.1016/j. jdiacomp.2005.05.011

Vallat, J.-M., Magy, L., Lagrange, E., Sturtz, F., Magdelaine, C., Grid, D., et al. (2007). Diagnostic value of ultrastructural nerve examination in charcot-marietooth disease: two CMT $1 \mathrm{~B}$ cases with pseudo-recessive inheritance. Acta Neuropathol. 113, 443-449. doi: 10.1007/s00401-007-0196-7

van Ballegooijen, A. J., Beulens, J. W. J., Keyzer, C. A., Navis, G. J., Berger, S. P., de Borst, M. H., et al. (2019). Joint association of vitamins D and K status with long-term outcomes in stable kidney transplant recipients. Nephrol. Dial. Transplantat.

van Ballegooijen, A. J., Cepelis, A., Visser, M., Brouwer, I. A., van Schoor, N. M., and Beulens, J. W. (2017a). Joint association of low vitamin D and vitamin $\mathrm{K}$ status with blood pressure and hypertension. Hypertension 69, 1165-1172. doi: 10.1161/HYPERTENSIONAHA.116.08869

van Ballegooijen, A. J., Pilz, S., Tomaschitz, A., Grübler, M. R., and Verheyen, N. (2017b). The synergistic interplay between vitamins D and K for bone and cardiovascular health: a narrative review. Int. J. Endocrinol. 2017:7454376. doi: 10.1155/2017/7454376

van Ballegooijen, A. J., Gansevoort, R. T., Lambers-Heerspink, H. J., de Zeeuw, D., Visser, M., Brouwer, I. A., et al. (2015). Plasma 1,25-dihydroxyvitamin D and the risk of developing hypertension: the prevention of renal and vascular end-stage disease study. Hypertension 66, 563-570. doi: 10.1161/HYPERTENSIONAHA. 115.05837

VanAmerongen, B. M., Dijkstra, C. D., Lips, P., and Polman, C. H. (2004). Multiple sclerosis and vitamin D: an update. Eur. J. Clin. Nutr. 58, 1095-1109. doi: 10.1038/sj.ejcn.1601952

Veenstra, T. D., Windebank, A. J., and Kumar, R. (1997). 1,25-Dihydroxyvitamin D3 regulates the expression of $\mathrm{N}-\mathrm{Myc}, \mathrm{c}-\mathrm{Myc}$, protein kinase $\mathrm{C}$, and transforming growth factor-beta2 in neuroblastoma cells. Biochem. Biophys. Res. Commun. 235, 15-18. doi: 10.1006/bbrc.1997.6718

Vuong, T. A., Leem, Y. E., Kim, B. G., Cho, H., Lee, S. J., Un Bae, G., et al. (2017). A sonic hedgehog coreceptor, $\mathrm{BOC}$ regulates neuronal differentiation and neurite 
outgrowth via interaction with ABL and JNK activation. Cell. Signal. 30, 30-40. doi: 10.1016/j.cellsig.2016.11.013

Westra, S., Krul-Poel, Y. H., van Wijland, H. J., ter Wee, M. M., Stam, F., Lips, P., et al. (2016). Effect of vitamin D supplementation on health status in nonvitamin D deficient people with type 2 diabetes mellitus. Endocr. Connect. 5, 61-69. doi: 10.1530/EC-16-0070

White, K. E., Evans, W. E., O’Riordan, J. L. H., Speer, M. C., Econs, M., LorenzDepiereux, B., et al. (2000). Autosomal dominant hypophosphataemic rickets is associated with mutations in FGF23. Nat. Genet. 26, 345-348. doi: 10.1038/ 81664

Wilkins, C. H., Sheline, Y. I., Roe, C. M., Birge, S. J., and Morris, J. C. (2006). Vitamin D deficiency is associated with low mood and worse cognitive performance in older adults. Am. J. Geriatr. Psychiatry 14, 1032-1040. doi: 10.1097/01.JGP.0000240986.74642.7c

Yang, S., Li, A., Wang, J. W., Liu, J., Han, Y., Zhang, W., et al. (2018). Vitamin D receptor: a novel therapeutic target for kidney diseases. Curr. Med. Chem. 25, 3256-3271. doi: 10.2174/09298673256661802141 22352

Yin, Y., Ni, J., Chen, M., Guo, Y., and Yeh, S. (2009). RRR-alpha-vitamin E succinate potentiates the antitumor effect of calcitriol in prostate cancer without overt side effects. Clin. Cancer Res. 15, 190-200. doi: 10.1158/1078-0432.CCR08-0910
Zárate, S., Stevnsner, T., and Gredilla, R. (2017). Role of estrogen and other sex hormones in brain aging. Neuroprotection and DNA repair. Front. Aging Neurosci. 9:430. doi: 10.3389/fnagi.2017.00430

Zhang, W., Chen, L., Zhang, L., Xiao, M., Ding, J., Goltzman, D., et al. (2015). Administration of exogenous $1,25(\mathrm{OH}) 2 \mathrm{D} 3$ normalizes overactivation of the central renin-angiotensin system in $1 \alpha(\mathrm{OH})$ ase knockout mice. Neurosci. Lett. 588, 184-189. doi: 10.1016/j.neulet.2015.01.013

Zhao, Y., Sun, Y., Ji, H. F., and Shen, L. (2013). Vitamin D levels in Alzheimer's and Parkinson's diseases: a meta-analysis. Nutrition 29, 828-832. doi: 10.1016/j.nut. 2012.11.018

Conflict of Interest Statement: The authors declare that the research was conducted in the absence of any commercial or financial relationships that could be construed as a potential conflict of interest.

Copyright (c) 2019 Faye, Poumeaud, Miressi, Lia, Demiot, Magy, Favreau and Sturtz. This is an open-access article distributed under the terms of the Creative Commons Attribution License (CC BY). The use, distribution or reproduction in other forums is permitted, provided the original author(s) and the copyright owner(s) are credited and that the original publication in this journal is cited, in accordance with accepted academic practice. No use, distribution or reproduction is permitted which does not comply with these terms. 